\title{
TITLE:
}

\section{Investment timing decisions of managers under endogenous contracts}

\author{
$\operatorname{AUTHOR}(\mathrm{S})$ :
}

Hori, Keiichi; Osano, Hiroshi

\section{CITATION:}

Hori, Keiichi ...[et al]. Investment timing decisions of managers under endogenous contracts. Journal of Corporate Finance 2014, 29: 607-627

ISSUE DATE:

2014-12

URL:

http://hdl.handle.net/2433/192938

\section{RIGHT:}

C 2013 Elsevier B.V.; この論文は出版社版でありません。引用の際には 出版社版をご確認ご利用ください。; This is not the published version. Please cite only the published version. 


\title{
Investment Timing Decisions of Managers under Endogenous Contracts*
}

\author{
Keiichi Hori ${ }^{\dagger}$ \\ Faculty of Economics, Ritsumeikan University \\ Hiroshi Osano $\ddagger$ \\ Institute of Economic Research, Kyoto University \\ June 8, 2011
}

Revised: April 2, 2012

Second revised: June 21, 2013

Third revised: September 26, 2013

\footnotetext{
${ }^{*}$ The authors would like to thank Kong-Pin Chen, Eric Chou, Shinsuke Ikeda, Xu Peng, Hirofumi Uchida, Noriyuki Yanagawa, the editors (Itay Goldstein and Dirk Hackbarth), an anonymous referee, and seminar and workshop participants at the Research Institute of Economy, Trade \& Industry (RIETI), the 2008 Contract Theory Workshop (Academia Sinica), the Monetary Economics Workshop, and Keio University for their helpful comments. This research is financially supported by the Japan Society for the Promotion of Science under Grant No.(C) 17530142 and the Nomura Foundation for Social Science.

${ }^{\dagger}$ Faculty of Economics, Ritsumeikan University, 1-1-1 Noji-higashi, Kusatsu, Shiga 525-8577, Japan.

${ }^{\ddagger}$ Corresponding author. Institute of Economic Research, Kyoto University, Sakyo-ku, Kyoto 606-8501, Japan. Phone: +81-75-753-7131, fax: +81-75-753-7138, e-mail: osano@kier.kyoto-u.ac.jp
} 


\title{
Investment Timing Decisions of Managers under Endogenous Contracts
}

\begin{abstract}
This paper considers what kind of managerial compensation contract is optimal for mitigating the moral hazard decision regarding investment timing. We examine the situation where the personal objectives of managers do not align with those of shareholders and where there is the possibility of project liquidation but where managerial compensation is endogenously determined. Using a real options approach, we show that restricted stock is optimal relative to stock options under various circumstances. However, we also suggest that stock options are more likely to be used instead of, or in addition to, restricted stock in firms with new debt financing and more impatient managers, diversified firms involving more complicated business activities, and firms with weaker corporate governance. In addition, we find that project start-up is more likely to be deterred by the greater likelihood of project liquidation and larger managerial effort cost, whereas the amount of stock-based managerial compensation is independent of the probability of liquidation but is increasing in managerial effort cost.
\end{abstract}

JEL Classification: D86, G30, G34, M52.

Keywords: agency conflicts, investment timing, real options, restricted stock, stock options. 


\section{Introduction}

This paper considers the problem of the optimal timing of investment decided by a manager under uncertainty and the possibility of project liquidation when his objectives are not aligned with those of shareholders but where his compensation is endogenously determined. In the literature analyzing investment decisions under uncertainty, the effect of the irreversibility of investment has been highlighted by McDonald and Siegel (1986) and Dixit and Pindyck (1994). This irreversibility creates an option value in waiting to launch a risky but value-increasing investment project and strongly affects the decision maker's incentives in undertaking the project.

However, in many modern corporations, the authority to choose when to launch investment projects is delegated to the manager. If the manager's objectives are not aligned with those of shareholders, the option value of waiting to invest for the manager differs from that for shareholders. Thus, managers are likely to determine the investment (or disinvestment) timing opportunistically (see Morellec (2004) and Lambrecht and Myers (2007, 2008)). In fact, managerial compensation also has an impact on option values for managers waiting to invest. Hence, shareholders should design managerial compensation schemes that succeed in inducing managers to choose the timing of investments more appropriately from the shareholders' point of view.

To capture these perspectives, we develop an agency conflict model with real options and the possibility of project liquidation, and analyze an optimal incentive contract for managers in a dynamic setting. The primary purpose of this paper is to examine what kind of contract is optimal in order to alleviate the manager's moral hazard incentive regarding investment timing when his objectives do not align with those of shareholders.

Our basic model builds on an agency setting in which the risk-neutral shareholders of a firm delegate decisions regarding commencing an investment project to a risk-neutral manager with limited liability and provide him with incentives to start the project. In the model, managers are assumed to be more impatient than, or equally as impatient as, the firm's initial shareholders and to incur effort costs for investment. As the firm's setup costs and the manager's effort costs for starting the project are sunk, the decision to launch the investment project is irreversible. Such irreversibility, together with the uncertain future value of the firm, means that there is an opportunity cost associated 
with investing today. This makes it essential for both the shareholders and the manager to select, as discussed in the real options literature, the appropriate time for starting the project.

However, where the manager's objectives do not align with those of shareholders, the start-up timing appropriate for the manager differs from that appropriate for shareholders. Besides, managers' decisions about whether to expend their effort costs to start the project are usually unobservable if there is a possibility of project failure; that is, liquidation at the start of the project. Then, it is impossible to write a complete contract specifying actions required for an efficient timing decision. However, even in this case, it is possible to write a contract contingent on the value of the firm's cash flow stream by using a stock-based compensation contract. Therefore, we consider how investment timing and optimal stock-based compensation schemes are endogenously determined together. An explicit example of our investment problem is that of a corporate manager who chooses the timing of investment in risky real projects.

Our main findings show that as long as agency conflicts exist:

(i) Restricted stock is optimal relative to stock options in various circumstances. However, the use of stock options can be more likely instead of, or in addition to, restricted stock in firms with new debt financing and more impatient managers (e.g., reorganized firms with new debt issues), diversified firms involving more complicated business activities (e.g., financial conglomerates), and firms with weaker corporate governance. ${ }^{1}$

(ii) The optimal trigger for the commencement of the project is increasing in the probability of liquidation, the volatility of the firm's cash flows, and the manager's effort cost, but decreasing in the degree of managerial impatience. Furthermore, the amount of stock-based managerial compensation is independent of the probability of liquidation, increasing in the manager's effort cost, and decreasing in the volatility of the firm's cash flow, and the degree of managerial impatience.

The intuition underlying these results is as follows. First, although the compensation aspect of stock options gives the manager a strong incentive to launch the project, the shareholders cannot make the manager fully internalize the benefits of the more efficient

\footnotetext{
${ }^{1}$ This conclusion does not necessarily suggest that observed compensation practice, such as stock options, suffers from any significant defect. Instead, it would be better to state that restricted stock is optimal if the manager's investment timing decisions are a major issue, as highlighted by McDonald and Siegel (1986) and Dixit and Pindyck (1994).
} 
timing of investment because there is a trade-off between the increasing incentive to commence the project earlier and the increasing dilution costs relating to the larger grant size of restricted stock. Hence, the optimal investment trigger from the viewpoint of the manager is higher than that of the shareholders. However, if the shareholders award stock options to the manager, the positive exercise price becomes an additional sunk cost to the manager. This causes further delay in the start-up of the project from the perspective of the shareholders. Thus, the exercise price needs to be minimized so that the restricted stock (equivalent to stock options with a zero exercise price) dominates the stock options with positive exercise prices. Conversely, if we consider the case of new debt financing with more impatient managers, diversified firms involving more complicated business activities, or firms with weaker corporate governance, then the optimal investment trigger of the manager would be lower than that of the shareholders. As a result, in these cases, the stock options would dominate the restricted stock.

Second, the uncertainty regarding project returns and the irreversibility of investments creates an incentive to postpone decisions. Thus, an increase in the probability of liquidation at the start of the project raises the risk of losing the sunk cost upon liquidation, thus delaying the project's start even further. An increase in the volatility of the firm's cash flow and an increase in the manager's effort cost also raise the value of the manager's option to wait, thereby motivating the manager to exercise the option to start the project later. By contrast, when the degree of managerial impatience increases, the value of the manager's option to wait decreases. Hence, an increase in the degree of managerial impatience induces earlier start-up of the project.

Third, as an increase in the liquidation probability at the start of the project merely raises the risk of losing the sunk cost upon liquidation, the grant size of restricted stock need not be adjusted so as to internalize this effect. Hence, the grant size of restricted stock is independent of the possibility of liquidation. Alternatively, the grant size of restricted stock is increasing in the manager's effort cost because the manager then needs to be compensated more. However, the grant size of restricted stock is decreasing in the volatility of the firm's cash flow stream and the degree of managerial impatience because these changes reduce the efficacy of restricted stock in motivating the manager to choose to launch the project earlier.

This paper continues a long line of research originating in McDonald and Siegel (1986) 
and Dixit and Pindyck (1994) using the real options model to study firms' investment decisions. Recently, several studies have explored the agency conflict problem in a real options model of a firm when there is ownership by outside stockholders but corporate control by inside managers. For example, Morellec (2004) and Lambrecht and Myers (2008) discuss the optimal capital structure and investment (or disinvestment) timing problems under manager-shareholder conflicts. Lambrecht and Myers (2007) also analyze the effects of golden parachutes (severance agreements) and other takeover mechanisms on the manager's disinvestment decision in declining firms. Elsewhere, Hugonnier and Morellec (2007) examine the impact of managerial risk aversion on the manager's investment decisions when managers face incomplete markets and are subject to the possibility of a control challenge. These studies assume that the manager's compensation is linear in firm value and the parameter value is fixed exogenously. Thus, shareholders cannot adjust the linear stock-based compensation scheme endogenously in order to provide incentives for the manager to choose the more appropriate timing of investment, although the scheme significantly affects the timing decisions. ${ }^{2}$

Unlike the real options literature mentioned above, Grenadier and Wang (2005) provide a model of investment timing under agency conflicts in corporate firms in which the managerial compensation contract is endogenously determined. ${ }^{3}$ Their focus, however, is on how shareholders discipline the patient or impatient manager by offering an incentive contract contingent on a trigger point. Hence, in contrast to the other literature on real options under agency conflicts, their model is formulated so that shareholders directly determine the timing of investment by choosing the trigger point, although the manager manipulates a hidden level of effort that affects the quality of the project. In this setting, if the manager cannot divert part of the project returns because of the absence of hidden information, the option to invest in projects of any quality is exercised at the full information level.

The main difference between our setting and existing real options studies under agency conflicts is that in our formulation, shareholders can provide incentives for the manager

\footnotetext{
${ }^{2}$ Although Lambrecht and Myers (2007) derive the optimal golden parachute (severance agreement), the other managerial compensation parameters in their model are fixed.

${ }^{3}$ In terms of other extension studies using the Grenadier and Wang (2005) model, Hori and Osano (2009) consider the replacement timing of the incumbent manager, while Shibata (2009) incorporates an audit technology.
} 
to choose the more appropriate timing of investment by adjusting the managerial compensation contract, even though the manager can still choose his most preferred timing of investment. Hence, the main contribution of the real options model in our paper is to clarify what kind of managerial contract is optimal in order to mitigate the manager's moral hazard decision regarding investment timing. This provides novel empirically testable implications concerning the choice of restricted stock and stock options. In addition, unlike other real options models, in our model, the sunk cost for the manager regarding the investment timing decision is summarized as his effort cost. As a result, we can easily derive the effect of the manager's sunk cost on investment timing and in doing so examine the empirically testable implications.

As a result, and unlike Grenadier and Wang (2005), the focus of our paper is on the situation in which none of the contracts contingent on a trigger point can be upheld, because the liquidation possibility at the start of the project renders unobservable whether or not the manager actually expends effort costs to start the project at the trigger point. In this situation, our focus is how the patient or impatient manager who chooses the timing of investment can be disciplined by means of a managerial compensation contract. However, to discipline the manager in this case, shareholders need to design a contract contingent on the value of the firm's cash flow stream; that is, a stock-based contract. This setting provides an opportunistic motivation for the manager choosing the timing of investment in the risky project. In contrast to Grenadier and Wang (2005), under agency conflicts over investment timing, we show that even in the absence of hidden information, investment in the project is delayed compared with the full information case. More importantly, we also suggest that restricted stock is optimal relative to stock options in various circumstances, although the optimal compensation contract derived in Grenadier and Wang is different from that commonly used in practice. Because most of the other existing real options models under agency conflicts assume that the managerial compensation contract is fixed as given, they cannot determine the optimal compensation schedule that mitigates the manager's moral hazard decision regarding investment timing. ${ }^{4}$

\footnotetext{
${ }^{4}$ Mæland (2006) also considers a real options model of investment timing under agency conflicts with endogenously determined compensation contracts. However, unlike our model, (i) there is no moral hazard in the manager's decision regarding investment timing because the owner can directly determine the investment timing by choosing the trigger point, (ii) the manager's compensation is paid only at the investment trigger point, as in Grenadier and Wang (2005), and (iii) private information leads to overinvestment for some parameter values, because the option value of investing decreases in time as
} 
As shown already, in our model, the commencement of the project is more likely to be delayed if the probability of the project's liquidation is greater. The effect of the project liquidation possibility on the investment timing is also investigated in Lyandres and Zhdanov (2010). However, they indicate that the possibility of default reduces the value of the option to wait and provides equity holders with an incentive to speed up investment. The difference between these results is because in Lyandres and Zhdanov (2010), the loss of the investment opportunity arises in the event of default before the investment cost has been paid, whereas in our model, the investment has been made and the investment cost paid before the project liquidation event.

The analysis in this paper is also related to the literature on optimal contracting models for CEO compensation (see Dittmann and Maug (2007) and Kadan and Swinkels (2008)). However, these studies employ a static optimal contracting model. By contrast, our paper is the first to solve the optimal contract offered by a firm in a continuous-time, real options setting where a manager chooses the timing of investment. In our model, agency conflicts in investment timing arise because the manager's preferred timing of investment differs from that of shareholders. The model can then derive an optimal structure for the compensation contract that provides incentives for the manager to choose the appropriate timing of investment in the risky project given these agency conflicts. In the static optimal contracting model, it is difficult to handle the agency conflicts over timing. Hence, the models imply that stock options are optimal if the manager is risk neutral or only has moderate levels of risk aversion (Dittmann and Maug (2007)), or if the risk-averse manager does not face higher bankruptcy risk (Kadan and Swinkels (2008)). By contrast, our model suggests that restricted stock is optimal relative to stock options in various circumstances. In addition, we clarify several economic conditions that make stock options more likely to be used instead of, or in addition to, restricted stock but that are not obtained in the frameworks in either Dittmann and Maug (2007) or Kadan and Swinkels (2008). The reason for this difference is that in our real options model, the choice between restricted stock and stock options depends on whether the manager's optimal timing of investment is later than that of shareholders.

In addition, the standard view of option-based compensation is that stock option contracts create incentives for risk taking. However, Ross (2004) has indicated that it is private information evolves stochastically. 
possible for the opposite to occur. Considering the possibility of loss aversion, de Meza and Webb (2007) also suggest a new reason why option-based compensation may lessen risk-taking behavior. In this paper, we further show that the manager's moral hazard incentive regarding the timing of investment provides a new reason that stock options may make the manager less inclined to take risky investment actions than does restricted stock compensation.

The rest of the paper is organized as follows. Section 2 presents the basic model and derives the full information solution as a benchmark. Section 3.1 examines the manager's optimal trigger strategy given a compensation contract. Section 3.2 characterizes the optimal compensation contract, and Section 3.3 discusses the comparative static results. Section 4 considers extensions of the basic model and assesses the robustness of our main results. Section 5 investigates the empirical implications of the model. The final section concludes the paper. The proofs of all propositions and lemmas are provided in the Appendix.

\section{The Basic Model}

\subsection{Investment technology.-}

We develop a continuous-time agency model in which a risk-neutral manager acts as an agent for a firm. We also use the term 'firm' to denote the initial shareholders. The manager has no personal financial resources, a reservation utility of zero, and limited liability. The initial shareholders own the firm, and their objective is to maximize the value of their payoff at time 0 . The firm is all-equity financed and operates in capital markets with no transaction costs, although the possibility of debt financing is examined in Section 4.5. Investors, including the initial shareholders, may lend and borrow freely at the risk-free rate $r$. However, we assume that the manager could be more impatient than the initial shareholders and that payoffs are valued by the manager with the discount rate $r+\xi$, where $\xi \geq 0 .{ }^{5}$ The case of the patient manager $(\xi<0)$ is discussed in Section 4.4.

We consider an investment project that only the manager can manage. Because the manager has specific skills in administering the investment project, he has decision rights over investment policies. Hence, the manager chooses the timing of the project start-up.

\footnotetext{
${ }^{5}$ For justification, see Grenadier and Wang (2005, Section 5).
} 
When the project is launched, the shareholders incur a fixed setup cost $C_{S}$. If $C_{S}$ is a monetary cost, the funds for $C_{S}$ are raised by issuing new equity to the initial shareholders. As new equity is issued to the initial shareholders, we need not discuss how much of the project should be financed with new equity or with cash (which equals revenues of the assets already in place and owned by the initial shareholders). We normalize the total number of outstanding shares to 1 after the issuing of new equity. In addition, the manager must expend effort so that the launched project generates a cash flow stream following the process of equation (1), defined below. The manager's effort inflicts physical disutility $C_{M}$ on him, which is measured in the same units as the firm's cash flow. The effort disutility cost $C_{M}$ creates incentives for the manager to choose an inefficient project start-up timing from the viewpoint of the firm. The two costs, $C_{S}$ and $C_{M}$, are sunk costs and make the decision regarding project commencement irreversible.

Now, the firm's instantaneous cash flow $x$ is realized with probability $1-\varepsilon$ when $C_{S}$ and $C_{M}$ are expended, and it evolves as a geometric Brownian motion:

$$
d x=\mu x d t+\sigma x d z
$$

where $\mu \in\left[(1 / 2) \sigma^{2}, r\right)$ is the instantaneous conditional expected percentage change in $x$ per unit of time, ${ }^{6} \sigma>0$ is the instantaneous conditional standard deviation per unit of time, and $d z$ is the increment of a standard Wiener process $(d z \sim N(0, d t))$. However, there is a probability $\varepsilon$ that no cash flow stream is generated even when $C_{S}$ and $C_{M}$ are expended. We further assume that if $C_{S}$ is not expended or if $C_{S}$ is expended but $C_{M}$ is not expended, no cash flow stream is generated with probability 1 . The probability $\varepsilon$ is the probability that the project is liquidated after $C_{S}$ and $C_{M}$ are expended. ${ }^{7}$

For the information structure, we assume that the manager's decision about whether to expend $C_{M}$ is unobservable, whereas the shareholders' decision about whether to expend

\footnotetext{
${ }^{6}$ The restriction $r>\mu$ is standard in the real options literature. The restriction $\mu \geq \frac{1}{2} \sigma^{2}$ ensures that the firm is a growing firm. However, our results hold even in the case of a declining firm.

${ }^{7}$ Practically, $\varepsilon$ may be viewed as a financial crisis risk, where the firm cannot start the project because the situation of distress ruins the profit opportunities of the project after $C_{S}$ and $C_{M}$ are expended. Alternatively, $\varepsilon$ may be interpreted as an authorization or litigation risk, where the authority does not allow the firm to start the project because of unexpected flaws in the project that are unrelated to the manager's effort decision but arise after $C_{S}$ and $C_{M}$ are expended. In addition, as discussed in Section 4.3 , we can obtain almost the same result by considering the possibility of the loss of the investment opportunity instead of the liquidation of the project.
} 
$C_{S}$ is observable and verifiable. All other variables, including the firm's cash flow stream, are publicly observed, and the diffusion process of $x$ is common knowledge.

\subsection{Contracts.-}

As the manager chooses the threshold at which he starts the project, the firm needs to motivate the manager to choose a project start-up timing that is appropriate for the initial shareholders, by offering a compensation contract at time 0 . Then, the firm might make compensation conditional upon $x$ and the commencement of the project. Because of this, we might consider compensation contracts that yield the manager a bonus payment of $\omega(>0)$ if the project is commenced at $x=x^{\prime}$, and 0 if the project is not commenced or if the project is commenced at $x \neq x^{\prime}$. If this kind of contract is feasible, the firm can always induce the manager to select the most convenient timing of investment from the viewpoint of the initial shareholders by adjusting $\omega$ and $x^{\prime}$.

In fact, this kind of contract is infeasible because there is a probability $\varepsilon$ of project failure, such that a court of law has trouble judging whether the manager really disrupted the process of expending the cost. Hence, even though the manager does not expend $C_{M}$, he can claim that the firm should pay $\omega$. Hence, this argument shows that the firm has no incentive to offer the above type of general contingent contract. ${ }^{8}$

Because of these reasons, we examine the case where the compensation contract at time 0 can be described by three parameters: the base salary at time $0, \phi$; the number of options on the firm's stock granted to the manager, $\alpha \in(0,1]$ (expressed as a fraction of all shares outstanding); and an exercise price, $P(\geq 0)$. Thus, a compensation contract can be represented by $(\phi, \alpha, P)$. Note that: (i) the case of $P>0$ corresponds to stock options, and (ii) the case of $P=0$ corresponds to restricted stock. ${ }^{9}$ Indeed, $\alpha=0$ can be excluded without loss of generality because the manager does not expend $C_{M}$ when $\alpha=0$; thus, no cash flow stream is generated in this case. The restrictions on $\alpha$ and $P$ are naturally attributed to the inherent features of restricted stock or stock options.

In the present stage of the analysis, we mention the case of $P<0$. If $P<0$, stock options are exercised immediately at time 0 using the options argument. The manager

\footnotetext{
${ }^{8}$ An alternative contract involves specifying a bonus payment $\omega$ contingent on the manager's report about his decision to expend $C_{M}$. However, in our setting, the manager's report on expending $C_{M}$ imposes no obligations on him. Hence, the firm has no incentive to offer this class of contract.

${ }^{9}$ Using the options argument, stock options with $P=0$ are immediately exercised at time 0 . Hence, they are viewed as restricted stock.
} 
has no incentive to delay exercising the stock options beyond time 0 because there is a negative sunk cost, and the exercising of stock options is instantaneous. Hence, we can view this case as a combination of restricted stock and a base salary at time 0 . Thus, without loss of generality, we can rule out this case.

Additionally, we impose the following restrictions on the contract $(\phi, \alpha, P)$. First, the manager's base salary at time 0 cannot be reduced below a certain threshold value. One plausible economic reason for the sticky base salary restriction is limited liability. Because we impose limited liability on the part of the manager, we add the sticky base salary constraint $\phi \geq 0$ for simplicity. ${ }^{10}$ However, in Section 4.1, we relax the sticky base salary constraint and show that our main results are preserved, particularly if the manager is more impatient than the initial shareholders.

Second, even if the manager must pay a positive exercise price $(P>0)$ and does not receive a sufficiently large base salary, the limited liability constraint can still hold at the time the stock options are exercised. This is because the manager may be allowed to sell part of the stock obtained by exercising stock options to pay the exercise price. ${ }^{11}$

Third, stock options are inalienable; that is, they cannot be sold, transferred, or assigned to a third party. Furthermore, we assume that stock obtained by the manager through exercising stock options cannot be sold, except for the purpose of paying the exercise price. ${ }^{12}$ We also assume that restricted stock granted to the manager is not tradable. This assumption is justified by the common practice that restricted stock cannot be freely sold by company executives and that executives are routinely required (through ownership guidelines imposed by the board) or pressured (by informed board requirements or through the desire to signal to markets) to hold more company stock than would be indicated by an optimal portfolio standpoint (see Hall and Murphy (2002)). Indeed, the efficacy of stock-based compensation as an incentive tool depends on its ability to expose the manager to the risks of the outcomes that his actions will produce. If the manager was able to diversify, or could somehow negate this risk, stock-based compensation would

\footnotetext{
${ }^{10}$ This kind of assumption is imposed in Dittmann and Maug (2007) and Kadan and Swinkels (2008).

${ }^{11}$ Otherwise, the manager may use "cashless exercise programs", under which he pays nothing and simply receives the value of the spread between the market price and the exercise price in shares of the company stock (see Hall and Murphy (2002)).

${ }^{12}$ In fact, because the assumption that the stock obtained by the manager through exercising stock options cannot be traded makes stock options more advantageous to the shareholders, the relaxation of this assumption does not modify our main results.
} 
not act as such an effective incentive instrument.

Finally, to obtain an analytical solution, we assume that there is no expiration date on stock options. ${ }^{13}$ In addition, we assume that the firm pays dividends after the project starts. ${ }^{14}$ We also assume that all granted options are allowed to vest whenever they are granted.

\subsection{The definition of equilibrium.-}

The equilibrium of the game is represented as follows. (i) At time 0, the firm offers the manager a compensation contract $(\phi, \alpha, P)$ to maximize the value of the shareholders' payoff. (ii) The manager determines the threshold for launching the project and the timing for exercising stock options to maximize the value of his payoff, given $(\phi, \alpha, P)$.

\subsection{The full information solution.-}

Before analyzing the equilibrium, we briefly review the full information solution used as a benchmark. The full information solution is derived by maximizing the value of the option to invest at $x_{0}$, provided that the manager's decision to expend the effort cost $C_{M}$ is publicly observable, that the project commencement is directly determined by the firm, and that the manager is compensated for $C_{M}$ so that he is induced to participate in the project.

The following proposition characterizes the full information solution.

Proposition 1: Let $x_{F I}$ denote the full information trigger for the commencement of the project, and let $V_{F I}(x)$ denote the full information value of the option to invest. Then,

$$
\begin{aligned}
\frac{x_{F I}}{r-\mu} & =\frac{1}{1-\varepsilon} \frac{\beta_{1}}{\beta_{1}-1}\left(C_{S}+C_{M}\right), \\
V_{F I}(x) & = \begin{cases}\left(\frac{x}{x_{F I}}\right)^{\beta_{1}}\left[\frac{(1-\varepsilon) x_{F I}}{r-\mu}-C_{S}-C_{M}\right] & \text { for } x<x_{F I}, \\
\frac{(1-\varepsilon) x}{r-\mu}-C_{S}-C_{M} & \text { for } x_{F I} \leq x,\end{cases}
\end{aligned}
$$

where $\beta_{1}=\frac{1}{2}-\frac{\mu}{\sigma^{2}}+\sqrt{\left(\frac{\mu}{\sigma^{2}}-\frac{1}{2}\right)^{2}+\frac{2 r}{\sigma^{2}}}>1$.

\footnotetext{
${ }^{13}$ As executive stock options typically have a 10-year expiration date, they are American call options with finite expiration dates. However, it is difficult to find analytical solutions in this case. See Karatzas and Shreve (1998) for details on the differences between American call options with finite expiration dates and those with infinite expiration dates.

${ }^{14}$ The dividend payment rule is exogenous, as commonly assumed in the real options literature.
} 
Note that $\beta_{1}$ is the positive root of the characteristic equation $\frac{1}{2} \sigma^{2} q(q-1)+\mu q=$ $r .{ }^{15}$ In the full information case, the discount rate $r$ is used because the firm directly determines the timing of the project's commencement.

Several remarks about this proposition are in order. First, because $\beta_{1}>1$ and $r>\mu$,

we have $\frac{(1-\varepsilon) x_{F I}}{r-\mu}>C_{S}+C_{M}$. In other words, because $\frac{(1-\varepsilon) x}{r-\mu}$ must be large enough to compensate for $C_{S}+C_{M}$, the firm does not start the project until the first time $x$ reaches the trigger $x_{F I}\left(>\frac{r-\mu}{1-\varepsilon}\left(C_{S}+C_{M}\right)\right)$. The intuitive reason is that there is an opportunity cost associated with investing today that is created by irreversible investment and the uncertain future value of $x$; that is, the option value of waiting to launch the project implies an action threshold at which the expected value from investing exceeds the cost. This feature cannot be captured in the static model. Second, the present value operator $\left(\frac{x}{x_{F I}}\right)^{\beta_{1}}$ can be interpreted as a stochastic discount factor that constitutes the present value of a dollar paid at the time of investment when the discount rate equals $r$. Finally, $x_{F I}$ does not depend on the initial value of $x_{0}$ because of the time-consistent structure of our model. Hence, $x_{F I}$ is determined independently of time.

\section{The Optimal Trigger Strategy and Compensation Contract}

In this section, we discuss the impact of agency conflicts, provided that the manager's decision to expend $C_{M}$ is unobservable and that the project start-up timing is determined by the manager. In the subsequent analysis, we work backward to derive the optimal trigger strategy and the optimal compensation contract. We first explore the manager's maximization problem with respect to the trigger points for launching the project and exercising stock options, and then examine the firm's maximization problem with respect to the compensation contract. Because we assume that no cash flow stream is generated unless $C_{M}$ is expended, we can focus on the case where the manager always chooses to expend $C_{M}$ at the launch of the project under $(\phi, \alpha, P)$ as long as his individual rationality constraint is satisfied. Thus, we need not consider the incentive compatibility constraint for the manager that induces him to expend $C_{M}$ at the launch of the project. This implies that we focus on resolving the manager's choice of project start-up timing strategy.

\subsection{The optimal trigger strategy for a given compensation contract.-}

\footnotetext{
${ }^{15}$ If $\beta_{1}$ is the negative root, $V_{F I}(x)$ is decreasing in $x$, which contradicts the intuitive explanation.
} 
We need to divide the analysis into the following two cases: (i) the manager first starts the project by expending $C_{M}$, and then exercises stock options by paying $P$ per share; and (ii) the manager first exercises stock options by paying $P$ per share, and then starts the project by expending $C_{M}$. Regardless of which case we deal with, we need to work backward to find the solution because the manager's problem is regarded as a two-stage sequential maximization problem.

We begin by discussing the first case. As the manager exercises the stock options after starting the project, we first solve the manager's problem of when to exercise the stock options, taking the compensation contract as given. The stock options examined here can be regarded as American call options with dividends and infinite expiration dates because we have assumed that there is no expiration date for the stock options and that the firm pays dividends after the project starts. After finding the value of the stock options held by the manager, along with the trigger value of $x$ at which the manager exercises the stock options, we next proceed to solve the manager's problem of when to launch the project, and derive the value of the manager's option to launch the project and the trigger value of $x$ for the project's commencement. At this stage, given the value of the stock options held by the manager and the corresponding trigger value of $x$ for exercising the stock options, the value of the manager's option to launch the project is determined. Hence, our twostage sequential maximization problem is to find the value of the compound options.

Indeed, using the result of Dixit and Pindyck (1994, Chapter 10.1), we can show that if $P>0$, the commencement of the project and the decision to exercise the stock options occur simultaneously. In other words, it will never be the case that the manager will start the project and then wait, rather than also exercising the stock options. ${ }^{16}$ Intuitively, the manager need not delay exercising the stock options, not only because the project start-up and the exercising of stock options are instantaneous but also because there are no other impediments to taking these actions simultaneously in any stage. Given this finding, we can transform the two-stage sequential maximization problem into a onestage maximization problem in which the manager simultaneously launches the project and exercises the stock options by expending $C_{M}$ and paying $P$ per share.

Similarly, using the result of Dixit and Pindyck (1994), we can prove that if $P>0$, the

\footnotetext{
${ }^{16}$ More specifically, the optimal solution indicates that the trigger level for launching the project in the first stage is larger than that for exercising the stock options in the second stage. As a result, the commencement of the project and the decision to exercise the stock options occur simultaneously.
} 
project start-up and the exercising of stock options occur simultaneously, even though we deal with the second case. Thus, if $P>0$, irrespective of the case we examine, we need only consider the one-stage maximization problem in which the manager simultaneously launches the project and exercises the stock options by expending $C_{M}$ and paying $P$ per share.

If $P=0$, the stock options are exercised immediately at time 0 and are reduced to restricted stock, as argued in Section 2.2. However, the manager's maximization problem for $P=0$ is the same as that for $P>0$, except that the manager need not pay $P$ per share at the start of the project. In other words, if $P=0$, the two-stage sequential maximization problem is reduced to a one-stage maximization problem with respect to the timing of the project's start-up (and simultaneous exercising of the stock options).

Let $x^{*}$ denote the optimal trigger value of $x$ at which the manager launches the project, and let $G(x)$ denote the value of the option to start the project for the manager. Now, solving the transformed one-stage maximization problem of the manager, we obtain the following proposition.

Proposition 2: If a contract $(\phi, \alpha, P)$ is given, then $x^{*}$ and $G(x)$ are

$$
\begin{gathered}
\frac{x^{*}}{r+\xi-\mu}=\frac{1}{1-\varepsilon} \frac{\gamma_{1}}{\gamma_{1}-1}\left[\frac{C_{M}}{\alpha}+(1-\varepsilon) P\right]>P, \\
G(x)= \begin{cases}\left(\frac{x}{x^{*}}\right)^{\gamma_{1}}\left[\alpha(1-\varepsilon)\left(\frac{x^{*}}{r+\xi-\mu}-P\right)-C_{M}\right] & \text { for } x<x^{*}, \\
\alpha(1-\varepsilon)\left(\frac{x}{r+\xi-\mu}-P\right)-C_{M} & \text { for } x^{*} \leq x,\end{cases}
\end{gathered}
$$

where $\gamma_{1}=\frac{1}{2}-\frac{\mu}{\sigma^{2}}+\sqrt{\left(\frac{\mu}{\sigma^{2}}-\frac{1}{2}\right)^{2}+\frac{2(r+\xi)}{\sigma^{2}}}>\beta_{1}>1$.

Note that $\gamma_{1}$ is the positive root of the characteristic equation $\frac{1}{2} \sigma^{2} q(q-1)+\mu q=r$ $+\xi$. In this case, the discount rate $r+\xi$ is used because the manager determines the project start-up timing.

Several remarks are in order. First, and as explained in Proposition 1, the option value for the manager of waiting to launch the project implies an action threshold, $x^{*}$, where the expected value for the manager from investing, $\frac{\alpha(1-\varepsilon) x^{*}}{r+\xi-\mu}$, exceeds the cost, $C_{M}+\alpha(1-$ $\varepsilon) P$, because $\gamma_{1}>1$ and $r+\xi>\mu$. Second, because $\frac{(1-\varepsilon)\left(\frac{x^{*}}{r+\xi-\mu}-P\right)}{P}=\frac{\gamma_{1}}{\gamma_{1}-1} \frac{C_{M}}{\alpha P}+\frac{1-\varepsilon}{\gamma_{1}-1}$, the manager is more likely to exercise the stock options deeper in the money, as $\gamma_{1}$ is smaller, 
$C_{M}$ is larger, $\alpha$ is smaller, $P$ is smaller, and $\varepsilon$ is smaller. Third, $x^{*}$ increases with $C_{M}$ and $\varepsilon$. Furthermore, $x^{*}$ increases in $P$ but decreases in $\alpha$. This implies that decreasing $P$ while increasing $\alpha$ induces the manager to launch the project earlier because the value of the option to start the project for the manager is then larger. Finally, the present value operator $\left(\frac{x}{x^{*}}\right)^{\gamma_{1}}$ can again be interpreted as a stochastic discount factor that constitutes the present value of a dollar paid at the time of investment when the discount rate equals $r+\xi$. Furthermore, it follows that $\left(\frac{x}{x^{*}}\right)^{\gamma_{1}} \leq\left(\frac{x}{x^{*}}\right)^{\beta_{1}}$ because $x<x^{*}$ and $\gamma_{1} \geq \beta_{1}$. This shows that a dollar received at the stopping time described by the trigger strategy $x^{*}$ is worth less to the manager than to the initial shareholders.

\subsection{The optimal contract.-}

To formalize the firm's maximization problem, we need to specify the values of the shareholders' and manager's payoffs at time 0, given a contract $(\phi, \alpha, P)$ and the manager's optimal trigger point $x^{*}$, derived in Proposition 2.

Let $W_{S}\left(x_{0}\right)$ and $W_{M}\left(x_{0}\right)$ denote the values of the shareholders' and manager's payoffs at time 0 , respectively. To simplify the analysis and to focus on the more interesting case, we assume that $x_{0}$ is not sufficiently large, so that $x_{0}<x^{*}{ }^{17}$ Then, using Proposition 2 and the fact that the shareholders' and manager's present value operators are represented by $\left(\frac{x_{0}}{x^{*}}\right)^{\beta_{1}}$ and $\left(\frac{x_{0}}{x^{*}}\right)^{\gamma_{1}}$, respectively, it follows that

$$
\begin{aligned}
& W_{S}\left(x_{0}\right)=-\phi+\left(\frac{x_{0}}{x^{*}}\right)^{\beta_{1}}\left[(1-\alpha) \frac{(1-\varepsilon) x^{*}}{r-\mu}+\alpha(1-\varepsilon) P-C_{S}\right], \\
& W_{M}\left(x_{0}\right)=\phi+\left(\frac{x_{0}}{x^{*}}\right)^{\gamma_{1}}\left[\alpha(1-\varepsilon)\left(\frac{x^{*}}{r+\xi-\mu}-P\right)-C_{M}\right] .
\end{aligned}
$$

Note that if the contract relation is organized, the firm pays the fixed base salary $\phi$ to the manager at time 0 .

Given Proposition 2, the firm's problem is presented as follows:

$$
\max _{\phi, \alpha, P}\left\{-\phi+\left(\frac{x_{0}}{x^{*}}\right)^{\beta_{1}}\left[(1-\alpha) \frac{(1-\varepsilon) x^{*}}{r-\mu}+\alpha(1-\varepsilon) P-C_{S}\right]\right\},
$$

\footnotetext{
${ }^{17}$ The sufficient condition for this is that $(1-\varepsilon) x_{0}<\frac{\beta_{1}}{\beta_{1}-1}\left[(r-\mu) C_{S}+\frac{\gamma_{1}}{\gamma_{1}-1}(r+\xi-\mu) C_{M}\right]$, which implies that the initial expected value of the firm's cash flow is smaller than (the multiplier $\left.\frac{\beta_{1}}{\beta_{1}-1}\right) \times[(r-$ $\mu) \times\left(\right.$ the firm's setup cost $\left.C_{S}\right)+\left(\right.$ the multiplier $\left.\frac{\gamma_{1}}{\gamma_{1}-1}\right) \times(r+\xi-\mu) \times\left(\right.$ the manager's effort cost $\left.C_{M}\right)$ ].
} 
subject to

$$
\begin{gathered}
\frac{x^{*}}{r+\xi-\mu}=\frac{1}{1-\varepsilon} \frac{\gamma_{1}}{\gamma_{1}-1}\left[\frac{C_{M}}{\alpha}+(1-\varepsilon) P\right], \\
\phi+\left(\frac{x_{0}}{x^{*}}\right)^{\gamma_{1}}\left[\alpha(1-\varepsilon)\left(\frac{x^{*}}{r+\xi-\mu}-P\right)-C_{M}\right] \geq 0, \\
\phi \geq 0, \\
1 \geq \alpha>0, \\
P \geq 0 .
\end{gathered}
$$

Here, the objective function is provided by $W_{S}\left(x_{0}\right)$. (IC) characterizes the incentive compatibility constraint for the manager with respect to $x$, which means that $x^{*}$ is derived from (4) in Proposition 2. (IR) expresses the individual rationality constraint for the manager, which guarantees that $W_{M}\left(x_{0}\right)$ is larger than or equal to the manager's reservation utility of zero. (BS) is the sticky base salary constraint, (SR) is the restriction on the shareholding ratios of the shareholders and the manager, and (EP) is the nonnegativity restriction on the exercise price of stock options. Note that as long as (IR) holds, we need not consider the incentive compatibility constraint for the manager that induces him to expend $C_{M}$, as argued at the beginning of this section.

Now, we show the following lemma:

Lemma 1: (IR) is not binding.

The intuition for the result of Lemma 1 is that the expected value for the manager from investing, $\frac{\alpha(1-\varepsilon) x^{*}}{r+\xi-\mu}$, exceeds the cost, $C_{M}+\alpha(1-\varepsilon) P$, because of (IC) and $\gamma_{1}>1$. As this, together with (BS), implies $\phi+\left(\frac{x_{0}}{x^{*}}\right)^{\gamma_{1}}\left[\alpha(1-\varepsilon)\left(\frac{x^{*}}{r+\xi-\mu}-P\right)-C_{M}\right]>0,(\mathrm{IR})$ is never binding. This intuition is also related to the investment rule of the standard real options model: the option is exercised at a trigger where the option value is positive.

Let $\left(\phi^{*}, \alpha^{*}, P^{*}\right)$ denote the solution to problem (6). Using Lemma 1 , we obtain the following proposition.

Proposition 3: The optimal commencement trigger is

$$
x^{*}=\frac{1}{1-\varepsilon} \frac{\beta_{1}}{\beta_{1}-1}\left[(r-\mu) C_{S}+\frac{\gamma_{1}}{\gamma_{1}-1}(r+\xi-\mu) C_{M}\right]>x_{F I} .
$$


Furthermore, restricted stock dominates stock options and the base salary, so the optimal compensation contract is characterized by

$$
\phi^{*}=P^{*}=0 \text { and } \alpha^{*}=\frac{\beta_{1}-1}{\beta_{1}} \frac{\gamma_{1}(r+\xi-\mu) C_{M}}{\left(\gamma_{1}-1\right)(r-\mu) C_{S}+\gamma_{1}(r+\xi-\mu) C_{M}} .
$$

The values of the shareholders' and manager's payoffs at time 0 are

$$
\begin{gathered}
W_{S}\left(x_{0}\right)=\left(\frac{x_{0}}{x^{*}}\right)^{\beta_{1}}\left[\frac{\beta_{1}\left(\gamma_{1}-1\right)(r-\mu) C_{S}+\gamma_{1}(r+\xi-\mu) C_{M}}{\beta_{1}\left(\gamma_{1}-1\right)(r-\mu) C_{S}+\beta_{1} \gamma_{1}(r+\xi-\mu) C_{M}} \frac{(1-\varepsilon) x^{*}}{r-\mu}-C_{S}\right]>0, \\
W_{M}\left(x_{0}\right)=\left(\frac{x_{0}}{x^{*}}\right)^{\gamma_{1}}\left[\frac{\beta_{1}-1}{\beta_{1}} \frac{\gamma_{1}(r+\xi-\mu) C_{M}}{\left(\gamma_{1}-1\right)(r-\mu) C_{S}+\gamma_{1}(r+\xi-\mu) C_{M}} \frac{(1-\varepsilon) x^{*}}{r+\xi-\mu}-C_{M}\right]>0 .
\end{gathered}
$$

The implications and intuitions for this proposition are as follows. First, the optimal commencement trigger $x^{*}$ is larger than the full information commencement trigger, $x_{F I}$, irrespective of whether $\gamma_{1}>\beta_{1}$ or $\gamma_{1}=\beta_{1}$. The reason is that the grant size of restricted stock under the optimal contract $\alpha^{*}$ is smaller than that required to attain $x_{F I} \cdot{ }^{18}$ This is because there is a trade-off between the increasing incentives to commence the project earlier and the increasing dilution costs relating to the larger grant size of restricted stock. As a result, the manager cannot fully internalize the benefits of the more efficient timing of investment. As an increase in the start-up trigger beyond $x_{F I}$ raises the value of the manager's option to launch the project, he has an incentive for this when $x^{*}>x_{F I}$.

Second, the exercise price $P^{*}$ is set to zero. As suggested, the project start-up and the exercising of stock options occur simultaneously, not only because they are instantaneous but also because there are no other impediments to taking the actions simultaneously in any stage. Then, there are two effects when $P$ increases. One effect is that the firm's revenues generated by the exercise price payment from the manager increase. This increases the value of the shareholders' option to launch the project. The other effect is that the trigger point for commencing the project increases because the manager must pay the higher $P$ as a sunk cost. Thus, increasing $P$ induces the manager to delay launching the project. The delay reduces the value of the shareholders' option to launch the project.

\footnotetext{
${ }^{18}$ From (IC) in (6), note that $x_{F I}$ would be attained if $\alpha$ were equal to $\frac{\beta_{1}-1}{\beta_{1}} \frac{\gamma_{1}}{\gamma_{1}-1} \frac{r+\xi-\mu}{r-\mu} \frac{C_{M}}{C_{S}+C_{M}}$.
} 
Indeed, as indicated, $x^{*}$ is greater than $x_{F I}$, so that the manager's optimal investment trigger is larger than that of the shareholders. The second effect always dominates the first because the positive exercise price further deters investment.

Third, the base salary $\phi^{*}$ is set to zero. It follows from (IC) and $\gamma_{1}>1$ that the individual rationality constraint is not binding because the expected value for the manager from investing exceeds the cost at $x^{*}$. Hence, an increase in $\phi$ only decreases the value of the shareholders' payoff at time 0 because it does not affect any of the incentives for the manager to start the project. Thus, it is evident from the sticky base salary constraint that $\phi^{*}=0$.

Several remarks about this proposition are in order. First, the project is commenced at a higher trigger level than $x_{F I}$, irrespective of whether $\gamma_{1}>\beta_{1}$ or $\gamma_{1}=\beta_{1}$. Indeed, as long as the manager's moral hazard motive exists, or as long as the manager's effort cost exists $\left(C_{M}>0\right)$, the trigger is determined at a higher level than $x_{F I}$. This perspective is not discussed in Grenadier and Wang's (2005) real options model, because they consider a setting in which the shareholders could directly determine the commencement trigger when $C_{M}=0$. Hence, in their model of hidden action only, all the trigger levels are determined at the full information level, regardless of whether $\gamma_{1}>\beta_{1}$ or $\gamma_{1}=\beta_{1}$. As a result, the trigger levels in their model are unaffected by the consideration of hidden action.

Second, the ratio $\frac{x^{*}}{x_{F I}}$ or the difference $x^{*}-x_{F I}$ measures the relative inefficiency of the trigger policy $x^{*}$. Because of $\frac{x^{*}}{x_{F I}}=\frac{1}{C_{S}+C_{M}}\left(C_{S}+\frac{\gamma_{1}}{\gamma_{1}-1} \frac{r+\xi-\mu}{r-\mu} C_{M}\right)(>1)$, the manager's trigger policy becomes less efficient as the setup cost of the shareholders $C_{S}$ decreases or the effort cost of the manager $C_{M}$ increases. It also follows from Proposition 4 in the next subsection that the manager's trigger policy becomes less efficient as managerial impatience $\xi$ decreases if $\sigma$ is sufficiently large. Although $\frac{x^{*}}{x_{F I}}$ is independent of the liquidation probability $\varepsilon, x^{*}-x_{F I}$ is increasing in $\varepsilon$. Hence, the greater probability of liquidation causes the manager's trigger policy to become less efficient.

Third, stock options are never optimal under the basic model setting. Instead, restricted stock is optimal, even with the manager's risk-neutral preferences. Furthermore, this result holds regardless of whether the manager is as patient as - or more patient than - the initial shareholders $\left(\gamma_{1}=\beta_{1}\right.$ or $\left.\gamma_{1}>\beta_{1}\right)$. Option-based compensation is often criticized for inducing "too much" risk taking by the manager. However, Ross (2004) indicates 
that the implicit assumption behind this argument is that the manager's von NeumannMorgenstern utility function has the same risk aversion over the entire relevant domain of outcomes. If not, he suggests that it is ambiguous whether option-based compensation encourages risk taking. De Meza and Webb (2007) also argue that the presence of loss aversion provides a further reason why risk taking may be lower with an option contract than with a share or other incentive scheme that does not protect against the downside. In this paper, we show that the manager's moral hazard incentive regarding the timing of investment gives another reason why stock options may make the manager less inclined to take risky investment actions than does restricted stock.

\subsection{Comparative statics.-}

We examine the effects of the key parameters of the model on $x^{*}$ and $\alpha^{*}$, given by Proposition 3. The key parameters are the liquidation probability $\varepsilon$, the volatility of the firm's cash flow stream $\sigma$, the manager's effort cost $C_{M}$, and the degree of managerial impatience $\xi$. As has been discussed, the parameter $\varepsilon$ may be viewed as the financial crisis risk or the authorization and litigation risk. $\sigma$ may be interpreted as the uncertainty of the business environment that the firm faces. $C_{M}$ may be the proxy for the complexity of the manager's task. $\xi$ may represent the manager's concerns about the firm's short-term performance or the threat to the manager from a stochastic termination, as suggested by Grenadier and Wang (2005). If $\xi$ is reduced when the manager has more job opportunities outside of the firm, $\xi$ becomes smaller as the managerial labor market becomes deeper.

Given the results of Proposition 3, we first obtain the following proposition.

Proposition 4: (i) $x^{*}$ is increasing in $\varepsilon, \sigma$, and $C_{M}$. If $\sigma$ is sufficiently large, $x^{*}$ is decreasing in $\xi$.

(ii) $\alpha^{*}$ is independent of $\varepsilon$ and increasing in $C_{M}$. In addition, if $\xi=0$ so that $\gamma_{1}=\beta_{1}$, then $\alpha^{*}$ is decreasing in $\sigma$. If $\sigma$ is sufficiently large, $\alpha^{*}$ is decreasing in $\xi$.

Result (i) indicates that the commencement trigger $x^{*}$ becomes higher as $\varepsilon$, $\sigma$, and $C_{M}$ increase. A larger $\varepsilon$ implies a greater liquidation probability, which raises the risk of losing the sunk cost upon liquidation and thus increases the required excess returns before launching the project. This increases $x^{*}$, all else being equal. In addition, for a given $\alpha$, a larger $\sigma$ raises the stochastic discount factor $\left(\frac{x_{0}}{x^{*}}\right)^{\beta_{1}}$ and $\left(\frac{x_{0}}{x^{*}}\right)^{\gamma_{1}}$ if $x^{*}$ is determined as in (4). This increases the value of the manager's option to wait, thereby motivating the 
manager to exercise the option to start the project later. The result that $x^{*}$ is increasing in $C_{M}$ is evident. By contrast, result (i) shows that when $\xi$ increases, $x^{*}$ decreases if $\sigma$ is sufficiently large. This is because the greater managerial impatience then decreases the value of the manager's option to wait. Hence, an increase in $\xi$ induces earlier start-up of the project.

Result (ii) shows that the grant size of restricted stock $\alpha^{*}$ is independent of $\varepsilon$. Because an increase in the liquidation probability merely raises the risk of losing the sunk cost upon liquidation, the expected value for the manager from investing, $\frac{(1-\varepsilon) x^{*}}{r+\xi-\mu}$, is independent of $\varepsilon$ for a given $\alpha$ if $x^{*}$ is determined by (4). As $\varepsilon$ does not affect any of the incentives for the manager to invest, the firm has no incentive to adjust the size of $\alpha$ so as to internalize the effect of $\xi$. However, result (ii) indicates that $\alpha^{*}$ increases with $C_{M}$. It is not surprising that the larger $C_{M}$ leads to the larger $\alpha^{*}$ because the manager needs to be more compensated when $C_{M}$ is larger. Furthermore, result (ii) suggests that $\alpha^{*}$ decreases with $\sigma$ if $\gamma_{1}=\beta_{1}$. A larger $\sigma$ increases the value of the manager's option to wait, as stated above. If the manager's impatience is not too different from the shareholders' $\left(\gamma_{1} \simeq \beta_{1}\right)$, an increase in $\sigma$ reduces the size of $\alpha$ used in the contract because this effect of $\sigma$ reduces the efficacy of restricted stock in motivating the manager to choose an earlier launching time for the project. However, if managerial impatience is sufficiently great, the firm may have to grant more $\alpha$ to compensate the manager for a decline in the option value (of investing) for the manager caused by a rise in $\sigma$. Result (ii) also implies that $\alpha^{*}$ decreases in $\xi$ if $\sigma$ is sufficiently large. Because greater managerial impatience then gives the manager more incentive to launch the project earlier for a given $\alpha$, the firm can reduce the grant size $\alpha$ used in the contract.

\section{Robustness Checks}

We now consider whether our main results remain valid, even when some of the assumptions made in the previous sections are modified.

\subsection{Negative base salaries.-}

Proposition 3 depends on the existence of the sticky base salary constraint, which does not allow for negative base salaries. Negative base salaries occur when managers invest some of their initial wealth in their company's securities. If base salaries can be neg- 
ative, we interpret this to mean that the contract requires managers to invest some of their private savings, in addition to their stock grants, in their company's securities. In fact, it seems very rare to specify a contract whereby managers must invest some of their private savings in the company's securities. In particular, we can almost entirely exclude this possibility for large publicly traded firms. However, if we allow base salaries to be negative, we present the following proposition.

Proposition 5: Suppose that $\phi$ is allowed to be negative.

(i) If $\gamma_{1}>\beta_{1}$, the optimal compensation contract, $\left(\phi^{*}, \alpha^{*}, P^{*}\right)$, is characterized by $\phi^{*}=$ $-\left(\frac{x_{0}}{x^{*}}\right)^{\gamma_{1}} \frac{C_{M}}{\gamma_{1}-1}, 0<\alpha^{*}<1$, and $P^{*}=0$. In addition, if $\xi$ is not sufficiently large, the optimal start-up trigger, $x^{*}$, must satisfy $x^{*}>x_{F I}$.

(ii) If $\gamma_{1}=\beta_{1}$, then $x^{*}$ and $\left(\phi^{*}, \alpha^{*}, P^{*}\right)$ are given by $x^{*}=x_{F I}, \phi^{*}=-\left(\frac{x_{0}}{x^{*}}\right)^{\beta_{1}} \frac{C_{M}\left(C_{S}+C_{M}\right)}{\left(\beta_{1}-1\right)\left[C_{S}+C_{M}-(1-\varepsilon) P^{*}\right]}$, $\alpha^{*}=\frac{C_{M}}{C_{S}+C_{M}-(1-\varepsilon) P^{*}}$, and $0 \leq P^{*} \leq \frac{C_{S}}{1-\varepsilon}$.

Even though base salaries are allowed to be negative, Proposition 5 suggests the following if the manager is more impatient than the initial shareholders $\left(\gamma_{1}>\beta_{1}\right)$. The optimal contract is made up of restricted stock but does not involve stock options, and the optimal trigger $x^{*}$ is larger than that at the full information level $x_{F I}$ if the manager's and the shareholders' impatience levels are not too different. Only if $\gamma_{1}=\beta_{1}$, is $x_{F I}$ attained, and the optimal contract cannot exclude stock options. Note that $\alpha^{*}=1$ if $P^{*}=\frac{C_{S}}{1-\varepsilon}$. Then, the optimal contract implies that the manager buys all the stock of the firm. Hence, as suggested in the static contract model, the full information allocation is achieved.

In the case of $\gamma_{1}=\beta_{1}$, the achievement of $x_{F I}$ implies that the moral hazard problem of the manager is fully resolved in this case. The indifference between restricted stock and stock options also depends on the fact that the choice of restricted stock or stock options does not affect any incentives for the manager to launch the project if base salaries can be negative. Indeed, if $\gamma_{1}=\beta_{1}$ and base salaries can be negative, these results are trivial because we end up analyzing the model without any limited liability constraints for the risk-neutral manager.

By contrast, the optimal contract does not involve stock options in the case of $\gamma_{1}>$ $\beta_{1}$. The greater managerial impatience $\gamma_{1}>\beta_{1}$ induces the firm not to set base salaries to be sufficiently negative because the firm needs to award the manager compensation as early as possible. This also implies that the firm needs to decrease the total compensation 
for the manager in this case by minimizing the exercise price; that is, by fixing $P^{*}$ at 0 . Furthermore, as the firm cannot set base salaries to be sufficiently negative, the grant size of restricted stock under the optimal contract must be smaller than that required to attain the full information allocation. This indirect effect, which raises the start trigger through a decrease in the grant size of restricted stock, dominates the direct effect of the greater managerial impatience, which may decrease the start trigger. Hence, $x^{*}$ is larger than $x_{F I}$.

These findings show that when the manager chooses the project start-up timing, our results - that restricted stock is optimal and $x^{*}$ is larger than $x_{F I}$-depend on the moral hazard incentive for the risk-neutral manager, as long as he is more impatient than the initial shareholders and is also constrained by the limited liability. However, if the manager is as impatient as the initial shareholders $\left(\gamma_{1}=\beta_{1}\right)$ and if there is no lower bound on how much the manager can be paid $(\phi<0)$, the firm can fix the optimal commencement trigger at $x_{F I}$ and can be indifferent between restricted stock and stock options, because the firm can resolve the moral hazard incentive for the risk-neutral manager even though $C_{M}>0 . .^{19}$

\subsection{The endogenous choice of the volatility.-}

In the previous sections, we assume that the volatility of the project is exogenously fixed. However, if the manager can choose to decrease or increase the volatility of the project, at the expense of a steady expected cash flow, the result of the dominance of restricted stock over stock options might be affected under certain circumstances.

To clarify this point, we assume that the manager has the option of choosing the project's volatility level as either $\sigma_{A}$ or $\sigma_{B}$. If the manager chooses $\sigma_{j}$, the corresponding $\mu$ in $(1)$ is $\mu_{j}(j=A, B)$. In the subsequent analysis, we need not specify any relation between $\sigma_{j}$ and $\mu_{j}$ to prove our result. Without loss of generality, we assume that the shareholders prefer to induce the manager to choose $\sigma_{A}$.

Let $x_{j}^{*}$ denote the optimal trigger value of $x$ at which the manager launches the project when the manager chooses $\sigma_{j}(j=A, B)$. Then, if the manager is induced to choose $\sigma_{A}$,

\footnotetext{
${ }^{19} \mathrm{By}$ contrast, in the static contracting model, tightening the limited liability constraint makes stock options more advantageous. See Dittmann and Maug (2007).
} 
the firm's problem is represented as follows:

$$
\max _{\phi, \alpha, P}\left\{-\phi+\left(\frac{x_{0}}{x_{A}^{*}}\right)^{\beta_{A}}\left[(1-\alpha) \frac{(1-\varepsilon) x_{A}^{*}}{r-\mu_{A}}+\alpha(1-\varepsilon) P-C_{S}\right]\right\},
$$

subject to

$$
\begin{gathered}
\frac{x_{A}^{*}}{r+\xi-\mu_{A}}=\frac{1}{1-\varepsilon} \frac{\gamma_{A}}{\gamma_{A}-1}\left[\frac{C_{M}}{\alpha}+(1-\varepsilon) P\right], \\
\frac{x_{B}^{*}}{r+\xi-\mu_{B}}=\frac{1}{1-\varepsilon} \frac{\gamma_{B}}{\gamma_{B}-1}\left[\frac{C_{M}}{\alpha}+(1-\varepsilon) P\right] \\
\phi+\left(\frac{x_{0}}{x_{A}^{*}}\right)^{\gamma_{A}}\left[\alpha(1-\varepsilon)\left(\frac{x_{A}^{*}}{r+\xi-\mu_{A}}-P\right)-C_{M}\right] \\
\geq \phi+\left(\frac{x_{0}}{x_{B}^{*}}\right)^{\gamma_{B}}\left[\alpha(1-\varepsilon)\left(\frac{x_{B}^{*}}{r+\xi-\mu_{B}}-P\right)-C_{M}\right], \\
\phi+\left(\frac{x_{0}}{x_{A}^{*}}\right)^{\gamma_{A}}\left[\alpha(1-\varepsilon)\left(\frac{x_{A}^{*}}{r+\xi-\mu_{A}}-P\right)-C_{M}\right] \geq 0, \\
\phi+\left(\frac{x_{0}}{x_{B}^{*}}\right)^{\gamma_{B}}\left[\alpha(1-\varepsilon)\left(\frac{x_{B}^{*}}{r+\xi-\mu_{B}}-P\right)-C_{M}\right] \geq 0,
\end{gathered}
$$

where $\beta_{A}=\frac{1}{2}-\frac{\mu_{A}}{\sigma_{A}^{2}}+\sqrt{\left(\frac{\mu_{A}}{\sigma_{A}^{2}}-\frac{1}{2}\right)^{2}+\frac{2 r}{\sigma_{A}^{2}}}$ and $\gamma_{j}=\frac{1}{2}-\frac{\mu_{j}}{\sigma_{j}^{2}}+\sqrt{\left(\frac{\mu_{j}}{\sigma_{j}^{2}}-\frac{1}{2}\right)^{2}+\frac{2(r+\xi)}{\sigma_{j}^{2}}}$ for $j$ $=A, B$.

Here, the objective function is provided by $W_{S}\left(x_{0}\right)$ if the manager chooses $\sigma_{A}$. (IC $\left.x_{A}^{*}\right)$ $\left(\left(\mathrm{IC} x_{B}^{*}\right)\right)$ characterizes the incentive compatibility constraint for the manager with respect to $x_{A}^{*}\left(x_{B}^{*}\right)$, which means that $x_{A}^{*}\left(x_{B}^{*}\right)$ is derived from (4) of Proposition 2 for $\gamma_{1}=\gamma_{A}\left(\gamma_{1}=\right.$ $\left.\gamma_{B}\right)$. (IC $\left.\sigma^{2}\right)$ represents the incentive compatibility constraint for the manager with respect to $\sigma^{2}$. (IRA) ((IRB)) expresses the individual rationality constraint for the manager, which guarantees that $W_{M}\left(x_{0}\right)$ is larger than or equal to the manager's reservation utility of zero if the manager chooses $\sigma_{A}\left(\sigma_{B}\right)$. Note that as long as (IRA) ((IRB)) holds, we need not consider the incentive compatibility constraint for the manager that induces him to expend $C_{M}$ if the manager chooses $\sigma_{A}\left(\sigma_{B}\right)$, as argued at the beginning of Section 3 . Finally, (LLR) corresponds to the conditions (BS), (SR), and (EP) in problem (6). 
Solving the firm's maximization problem, we obtain the following proposition.

Proposition 6: Even though the manager optimally chooses the volatility of the cash flow, restricted stock dominates stock options and the base salary.

Intuitively, even though the manager's volatility choice is endogenous, the incentive compatibility constraint for the manager with respect to the volatility has no effect on the choice of $P$. Therefore, the result of the dominance of restricted stock over stock options and the base salary is unaffected by endogenizing the manager's choice of the volatility of the cash flow.

\subsection{The possibility of the loss of the investment opportunity.-}

In the previous sections, we have assumed that a project's failure, corresponding to zero cash flow for the firm, always occurs immediately after its commencement, according to some fixed probability. Instead, we may assume that the investment opportunity can be lost at any given point in time with some probability. However, if the investment opportunity is observable and verifiable, the 'general' contract mentioned in Section 2.2 is feasible because the commencement of the project is also verifiable by outside parties. Hence, the firm can offer a compensation contract that yields the manager a bonus payment $\omega$ if the project is commenced at $x=x^{\prime}$, and 0 if the project is not commenced at all or if the project is commenced at $x \neq x^{\prime}$. As a result, if the investment opportunity is lost at any given point in time with some probability, the firm can always induce the manager to choose the most convenient investment timing from the viewpoint of the initial shareholders. Hence, the firm need not use any kind of stock-based compensation.

On the other hand, if the loss of the investment opportunity is not verifiable, the firm needs to use stock-based compensation contracts because the firm cannot use the above 'general' contract. To analyze the effect of the loss of the investment opportunity in this case, let us denote by $\lambda$ the hazard rate for the loss of the investment opportunity. Then, the probability that the loss of the investment opportunity will occur at time $t$ is given by $e^{-\lambda t}$, while the probability that the loss will not occur at time $t$ is given by $1-e^{-\lambda t}$. Repeating the arguments of Sections 2 and 3, we can show that the results of Propositions 1-3 still hold, although (i) the terms $r-\mu$ and $r+\xi-\mu$ in Propositions 1-3 are replaced with $r+\lambda-\mu$ and $r+\lambda+\xi-\mu$, and (ii) $\beta_{1}$ and $\gamma_{1}$ are determined by $\beta_{1}=\frac{1}{2}-\frac{\mu}{\sigma^{2}}$ $+\sqrt{\left(\frac{\mu}{\sigma^{2}}-\frac{1}{2}\right)^{2}+\frac{2(r+\lambda)}{\sigma^{2}}}$ and $\gamma_{1}=\frac{1}{2}-\frac{\mu}{\sigma^{2}}+\sqrt{\left(\frac{\mu}{\sigma^{2}}-\frac{1}{2}\right)^{2}+\frac{2(r+\lambda+\xi)}{\sigma^{2}}}$. Hence, even though 
the loss of the investment opportunity is not verifiable, the result of the dominance of restricted stock over stock options and the base salary is unaffected. ${ }^{20}$

\subsection{Patient manager.-}

Even though the manager is less impatient than the shareholders $(\xi<0)$, the logic of $P^{*}=0$ in Proposition 3 holds as long as $\xi$ is not so small that $\gamma>1$. Hence, although the manager is less impatient than the shareholders, restricted stock continues to dominate stock options and the base salary if the manager's discount rate is not sufficiently small relative to the shareholders' discount rate.

\subsection{Debt financing.-}

In the previous sections, the firm does not finance investment projects with risky debt. However, if we consider the possibility of debt financing, our main results may not be robust. In Section 4.5.1, we first discuss the effect of new debt financing when the firm has no debt before the commencement of the project. In Section 4.5.2, we clarify the implications of the presence of already outstanding debt when the firm issues debt before the start of the project.

4.5.1. New debt financing To examine this case, we need to modify the basic model. First, we assume that the firm issues perpetual debt with principal $D$ to finance part of the investment project and must make a fixed instantaneous contractual coupon payment $s$ to debt holders at any point of time. For simplicity, we assume that the coupon payment $s$ is predetermined, although the firm's debt level is endogenously determined at a level that induces debt holders to participate in the debt market. ${ }^{21}$ Second, we assume that full debt service $s$ is obtained by lenders as long as the firm continues to be viable. However, if the firm fails to service the debt, the lenders take over the firm. Hence, the value of equity at default is zero. Third, we abstract from bankruptcy costs. Finally, like the

\footnotetext{
${ }^{20}$ Instead of assuming the hazard rate function, we can characterize the effect of the loss of the investment opportunity by the following mixed Brownian motion jump process: $d x_{t}=\mu x_{t} d t+\sigma x_{t} d z_{t}+$ $x_{t} d y_{t}$. Here, $d y_{t}$ is the following Poisson process, for which the arrival time of the loss of the investment opportunity follows a Poisson distribution: $d y_{t}=0$ with probability $1-\lambda d t$; and $d y_{t}=-1$ with probability $\lambda d t$. Note that $d z_{t}$ and $d y_{t}$ are independent. Using this stochastic process, we can derive the same result as that in the case of the hazard rate function. For a discussion of the jump process, see Dixit and Pindyck (1994).

${ }^{21}$ If $D<C_{S}$, the remaining amount of $C_{S}-D$ is financed by equity. If $C_{S}<D$, the excess amount of funds $D-C_{S}$ is saved at the interest rate $r$.
} 
investment decision, the manager makes the decision on whether to default on the loan.

Given the above modifications, the manager's optimization is given by

$$
W_{M}^{b}\left(x_{0}\right)=\max _{T_{i}, T_{d}} E\left\{\int_{T_{i}}^{T_{d}} e^{-(r+\xi) t} \alpha(1-\varepsilon)\left(x_{t}-s\right) d t-e^{-(r+\xi) T_{i}}\left[\alpha(1-\varepsilon) P+C_{M}\right]\right\}+\phi
$$

where $E$ is the expectation operator, $T_{i}$ is a stopping time at which the investment option is exercised, and $T_{d}$ is a stopping time at which the default option is exercised (after the investment). Let $\left(T_{i}^{*}, T_{d}^{*}\right)$ denote the optimal stopping times. Indeed, as shown in the previous sections, the optimal stopping time rule is expressed in the form of the optimal thresholds; namely, the optimal investment threshold, $x_{i}^{*}$, and the optimal default threshold, $x_{d}^{*}$.

Given $\left(T_{i}^{*}, T_{d}^{*}\right)$ and $x_{i}^{*}$, the shareholders' (or the firm's) optimization problem can be written as

$$
\begin{aligned}
W_{S}^{b}\left(x_{0}\right)= & \max _{\substack{1 \geq \alpha>0, P \geq 0, \phi \geq 0 \\
-\phi}} E\left\{\int_{T_{i}^{*}}^{T_{d}^{*}} e^{-r t}(1-\alpha)(1-\varepsilon)\left(x_{t}-s\right) d t+e^{-r T_{i}^{*}}\left[\alpha(1-\varepsilon) P-C_{S}+D\left(x_{i}^{*}\right)\right]\right\} \\
& -1\}
\end{aligned}
$$

Here, $D\left(x_{i}\right)$ is the value of the debt when the investment option is exercised.

As in the previous sections, we now work backward to derive the optimal trigger strategies and compensation contract. We first explore the manager's maximization problem with respect to the trigger point for defaulting on the loan after investing in the project. The following proposition gives the optimal default threshold, the value of the manager's payoff at the time the investment option is exercised, and the value of debt at the time the investment option is exercised.

Proposition 7: The optimal default trigger is

$$
\frac{x_{d}^{*}}{r+\xi-\mu}=\frac{\gamma_{2}}{\gamma_{2}-1} \frac{s}{r+\xi}<\frac{s}{r+\xi}
$$

where $\gamma_{2}$ is the negative root of the characteristic equation $\frac{1}{2} \sigma^{2} q(q-1)+\mu q=r+\xi$; that is, $\gamma_{2}=\frac{1}{2}-\frac{\mu}{\sigma^{2}}-\sqrt{\left(\frac{\mu}{\sigma^{2}}-\frac{1}{2}\right)^{2}+\frac{2(r+\xi)}{\sigma^{2}}}$. If the investment option is exercised, the value of the manager's payoff and the value of debt at the time the investment option is 
exercised are

$$
\begin{gathered}
W_{M}^{b}\left(x_{i}^{*}\right)=\alpha(1-\varepsilon)\left\{\left[\frac{x_{i}^{*}}{r+\xi-\mu}-P-\frac{s}{r+\xi}-\frac{C_{M}}{\alpha(1-\varepsilon)}\right]\right. \\
\left.-\left(\frac{x_{i}^{*}}{x_{d}^{*}}\right)^{\gamma_{2}}\left(\frac{x_{d}^{*}}{r+\xi-\mu}-\frac{s}{r+\xi}\right)\right\}>0, \\
D\left(x_{i}^{*}\right)=(1-\varepsilon)\left[\frac{s}{r}+\left(\frac{x_{i}^{*}}{x_{d}^{*}}\right)^{\beta_{2}}\left(\frac{x_{d}^{*}}{r-\mu}-\frac{s}{r}\right)\right],
\end{gathered}
$$

where $\beta_{2}$ is the negative root of the characteristic equation $\frac{1}{2} \sigma^{2} q(q-1)+\mu q=r$; that is, $\beta_{2}=\frac{1}{2}-\frac{\mu}{\sigma^{2}}-\sqrt{\left(\frac{\mu}{\sigma^{2}}-\frac{1}{2}\right)^{2}+\frac{2 r}{\sigma^{2}}}$.

We next examine the manager's maximization problem with respect to the trigger point for launching the project. The following proposition yields the optimal investment threshold and the values of the shareholders' and the manager's payoffs at time 0 .

Proposition 8: The optimal investment trigger satisfies

$$
\begin{aligned}
\frac{x_{i}^{*}}{r+\xi-\mu} & =\frac{\gamma_{1}}{\gamma_{1}-1}\left[P+\frac{s}{r+\xi}+\frac{C_{M}}{\alpha(1-\varepsilon)}\right] \\
& +\frac{\gamma_{1}-\gamma_{2}}{\gamma_{1}-1}\left(\frac{x_{i}^{*}}{x_{d}^{*}}\right)^{\gamma_{2}}\left(\frac{x_{d}^{*}}{r+\xi-\mu}-\frac{s}{r+\xi}\right) .
\end{aligned}
$$

If the investment option is exercised, the values of the shareholders' and the manager's payoffs at time 0 are

$$
\begin{gathered}
W_{S}^{b}\left(x_{0}\right)=-\phi+\left(\frac{x_{0}}{x_{i}^{*}}\right)^{\beta_{1}}\left[(1-\alpha)(1-\varepsilon)\left(\frac{x_{i}^{*}}{r-\mu}-\frac{s}{r}\right)+\alpha(1-\varepsilon) P\right] \\
-\left(\frac{x_{0}}{x_{i}^{*}}\right)^{\beta_{1}}\left[C_{S}-D\left(x_{i}^{*}\right)+\left(\frac{x_{i}^{*}}{x_{d}^{*}}\right)^{\beta_{2}}(1-\alpha)(1-\varepsilon)\left(\frac{x_{d}^{*}}{r-\mu}-\frac{s}{r}\right)\right], \\
W_{M}^{b}\left(x_{0}\right)=\phi+\left(\frac{x_{0}}{x_{i}^{*}}\right)^{\gamma_{1}}\left[\alpha(1-\varepsilon)\left(\frac{x_{i}^{*}}{r+\xi-\mu}-P-\frac{s}{r+\xi}\right)-C_{M}\right] \\
-\left(\frac{x_{0}}{x_{i}^{*}}\right)^{\gamma_{1}}\left(\frac{x_{i}^{*}}{x_{d}^{*}}\right)^{\gamma_{2}} \alpha(1-\varepsilon)\left(\frac{x_{d}^{*}}{r+\xi-\mu}-\frac{s}{r+\xi}\right)>0 .
\end{gathered}
$$


Now, given Propositions 7 and 8, the firm's optimization problem can be represented as follows:

$$
\max _{\phi, \alpha, P} W_{S}^{b}\left(x_{0}\right)
$$

subject to (15), $W_{M}^{b}\left(x_{0}\right) \geq 0, \phi \geq 0,1 \geq \alpha>0$, and $P \geq 0$. Note that (15) is the incentive-compatibility condition for the manager, $W_{M}^{b}\left(x_{0}\right) \geq 0$ is the individual rationality condition for the manager, and the final three constraints correspond to the conditions $(\mathrm{BS}),(\mathrm{SR})$, and (EP) in problem (6).

Solving problem (18), we obtain the following proposition.

Proposition 9: Suppose that $\xi(\geq 0)$ is sufficiently small. Then, $P=\phi=0$ as long as the investment option is exercised. Hence, even though debt financing is used, restricted stock still dominates stock options and the base salary.

Intuitively, if $\xi$ is sufficiently small, the option value of investing at the optimal investment trigger is positive for the manager, even when evaluated at the shareholders' discount rate, although we do consider the coupon payment and the default loss. Then, the shareholders prefer to induce the manager to exercise the investment option as early as possible. Thus, the exercise price must be set to zero. Hence, even though debt financing is exploited, restricted stock becomes better at providing the manager with a greater incentive to launch the risky project because it does not force the manager to pay any positive exercise price.

However, if $\xi$ is not sufficiently small, the option value of investing at the optimal investment trigger may be negative for the manager when it is evaluated at the shareholders' discount rate, because the discounted values of the coupon payment and the default loss may be sufficiently large. In this case, the shareholders do not prefer to induce the manager to exercise the investment option as early as possible. Hence, the exercise price need not be necessarily zero. Therefore, if the manager's discount rate is sufficiently larger than the shareholders' rate, the exercise price may be positive, so that stock options dominate restricted stock.

Realistically, managers in reorganized firms are more concerned about the firms' shortterm performance, while the outstanding debt of these firms is likely to be abandoned. Hence, if these firms issue new debt, stock options would be preferred to restricted stock as compensation for the managers. 
4.5.2. Outstanding debt ${ }^{22}$ If there is outstanding debt before the start of the project, Lyandres and Zhdanov (2010) suggest that the accelerated investment effect of debt leads to a positive relation between the firm's coupon rate and the speed of the exercise of its investment option. This effect crucially depends on the assumption that the investment opportunity is lost given the default of debt from the shareholders' perspective. As a result, the presence of outstanding debt before the start of the project reduces the value of the option to wait and induces the willingness of shareholders to exercise their investment option earlier. However, the same mechanism works for the manager when he is awarded stock-based compensation. Hence, if the shareholders are more willing to exercise their investment option earlier than the manager, restricted stock dominates stock options from the shareholders' perspective because the positive exercise price delays the manager's investment timing further; otherwise, stock options dominate restricted stock.

\subsection{Multiple projects.-}

Our basic model can be extended to the case of multiple projects, in which there is more than one potential investment opportunity available. Suppose that the manager has the option of commencing two projects, $j=m, n$. If he commences project $j$, the firm's instantaneous cash flow $x_{j}$ is realized with probability $1-\varepsilon_{j}$ when the investment cost $C_{S j}$ and the manager's effort cost $C_{M j}$ are expended, and evolves as a geometric Brownian motion:

$$
d x_{j}=\mu_{j} x_{j} d t+\sigma_{j} x_{j} d z_{j}
$$

where $\mu_{j} \in\left[(1 / 2) \sigma^{2}, r\right)$ is the instantaneous conditional expected percentage change in $x_{j}$ per unit of time, $\sigma_{j}>0$ is the instantaneous conditional standard deviation per unit of time, and $d z_{j}$ is the increment of a standard Wiener process $\left(d z_{j} \sim N(0, d t)\right)$. However, there is a probability $\varepsilon_{j}$ that no cash flow stream is generated, even when $C_{S_{j}}$ and $C_{M_{j}}$ are expended. We further assume that if $C_{S j}$ is not expended or if $C_{S j}$ is expended but $C_{M j}$ is not expended, then the probability that no cash flow stream is generated is 1 . For simplicity, $d z_{m}$ and $d z_{n}$ are independently distributed.

In this case, in order to finance the investment cost and to motivate the manager, we consider the following equity finance and compensation contracts. At time 0, the firm issues equity to the initial shareholders on the condition that the initial shareholders pay

\footnotetext{
${ }^{22}$ This discussion follows the suggestion from an anonymous referee.
} 
$C_{S m}$ when project $m$ is commenced. Then, the firm offers the manager a compensation contract: a base salary at time $0, \phi(\geq 0)$; a number of options on the firm's stock granted to the manager if project $m$ is commenced, $\alpha \in(0,1]$; and an exercise price for stock options if project $m$ is commenced, $P(\geq 0)$. At the commencement of project $n$, in order to finance the investment cost $C_{S n}$, the firm issues new equity and distributes it on a pro rata basis to the initial shareholders and the manager. Thus, this framework captures a situation in which the time at which the manager exercises the investment option does not necessarily coincide with the time at which he exercises the stock option.

Without loss of generality, we assume that project $m$ is commenced before project $n$. For simplicity, we also assume that the commencement of project $m$ is not required before commencing project $n$.

Now, under the above setting, the manager's optimization can be formalized by

$$
\begin{aligned}
W_{M}^{m n}\left(x_{m 0}, x_{n 0}\right) & =\max _{T_{m i}, T_{n i}} E\left\{\int_{T_{m i}}^{\infty} e^{-(r+\xi) t} \alpha\left(1-\varepsilon_{m}\right) x_{m} d t-e^{-(r+\xi) T_{m i}}\left[\alpha\left(1-\varepsilon_{m}\right) P+C_{M m}\right]\right. \\
& \left.+\int_{T_{n i}}^{\infty} e^{-(r+\xi) t} \alpha\left(1-\varepsilon_{n}\right) x_{n} d t-e^{-(r+\xi) T_{n i}}\left[\alpha C_{S n}+C_{M n}\right]\right\}+\phi
\end{aligned}
$$

where $\left(x_{m 0}, x_{n 0}\right)$ is the initial value of $\left(x_{m}, x_{n}\right)$ at time $0, E$ is the expectation operator, and $T_{j i}$ is a stopping time at which project $j$ is commenced. Let $\left(T_{m i}^{*}, T_{n i}^{*}\right)$ denote the optimal stopping times.

Given $\left(T_{m i}^{*}, T_{n i}^{*}\right)$, the shareholders' (or the firm's) optimization problem can also be characterized by

$$
\begin{aligned}
W_{S}^{m n}\left(x_{m 0}, x_{n 0}\right) & =\max _{1 \geq \alpha>0, P \geq 0, \phi \geq 0} E\left\{\int_{T_{m i}^{*}}^{\infty} e^{-r t}(1-\alpha)\left(1-\varepsilon_{m}\right) x_{m} d t+e^{-r T_{m i}^{*}}\left[\alpha\left(1-\varepsilon_{m}\right) P-C_{S m}\right]\right. \\
& \left.+\int_{T_{n i}^{*}}^{\infty} e^{-r t}(1-\alpha)\left(1-\varepsilon_{n}\right) x_{n} d t-e^{-r T_{n i}^{*}}(1-\alpha) C_{S n}\right\}-\phi
\end{aligned}
$$

As in the previous sections, the optimal stopping time rule is again expressed in the form of the optimal threshold: the optimal investment threshold of the project $j, x_{j i}^{*}$, at which the manager launches the project $j$. Because $x_{m}$ and $x_{n}$ evolve independently, 
using the arguments in Section 3, the firm's problem is characterized as follows:

$$
\begin{aligned}
& \max _{\phi, \alpha, P}-\phi+\left(\frac{x_{0}}{x_{m}^{*}}\right)^{\beta_{m}}\left[(1-\alpha) \frac{\left(1-\varepsilon_{m}\right) x_{m}^{*}}{r-\mu_{m}}+\alpha\left(1-\varepsilon_{m}\right) P-C_{S m}\right] \\
& +\left(\frac{x_{0}}{x_{n}^{*}}\right)^{\beta_{n}}(1-\alpha)\left[\frac{\left(1-\varepsilon_{n}\right) x_{n}^{*}}{r-\mu_{n}}-C_{S n}\right]
\end{aligned}
$$

subject to

$$
\begin{gathered}
\frac{x_{m}^{*}}{r+\xi-\mu_{m}}=\frac{1}{1-\varepsilon_{m}} \frac{\gamma_{1}}{\gamma_{1}-1}\left[\frac{C_{M m}}{\alpha}+\left(1-\varepsilon_{m}\right) P\right], \\
\frac{x_{n}^{*}}{r+\xi-\mu_{n}}=\frac{1}{1-\varepsilon_{n}} \frac{\gamma_{1}}{\gamma_{1}-1}\left(C_{S n}+\frac{C_{M n}}{\alpha}\right), \\
\alpha\left(1-\varepsilon_{n}\right) \frac{x_{n}^{*}}{r+\xi-\mu_{n}}-\alpha C_{S n}-C_{M n} \geq 0, \\
\phi+\left(\frac{x_{0}}{x_{m}^{*}}\right)^{\gamma_{m}}\left[\alpha\left(1-\varepsilon_{m}\right)\left(\frac{x_{m}^{*}}{r+\xi-\mu_{m}}-P\right)-C_{M m}\right] \\
+\left(\frac{x_{0}}{x_{n}^{*}}\right)^{\gamma_{n}}\left[\alpha\left(1-\varepsilon_{n}\right) \frac{x_{n}^{*}}{r+\xi-\mu_{n}}-\alpha C_{S n}-C_{M n}\right] \geq 0, \\
\phi \geq 0,1 \geq \alpha>0, P \geq 0,
\end{gathered}
$$

where $\beta_{j}=\frac{1}{2}-\frac{\mu_{j}}{\sigma_{j}^{2}}+\sqrt{\left(\frac{\mu_{j}}{\sigma_{j}^{2}}-\frac{1}{2}\right)^{2}+\frac{2 r}{\sigma_{j}^{2}}}$ and $\gamma_{j}=\frac{1}{2}-\frac{\mu_{j}}{\sigma_{j}^{2}}+\sqrt{\left(\frac{\mu_{j}}{\sigma_{j}^{2}}-\frac{1}{2}\right)^{2}+\frac{2(r+\xi)}{\sigma_{j}^{2}}}$ for $j=$ $m, n$.

Here, the objective function is the value of the shareholders' payoff at time $0,\left(\mathrm{IC}_{j}\right)$ is the incentive compatibility constraint for the manager with respect to $x_{j}^{*}(j=m, n),\left(\operatorname{IR}_{n}\right)$ is the individual rationality constraint for the manager upon the commencement of project $n$, and $\left(\mathrm{IR}_{m n}\right)$ is the individual rationality constraint for the manager at time 0 . Note that as long as $\left(\mathrm{IR}_{n}\right)$ and $\left(\mathrm{IR}_{m n}\right)$ hold, we need not consider any incentive compatibility constraints for the manager that induce him to expend $\alpha C_{S n}, C_{M m}$, and $C_{M n}$, as argued at the beginning of Section 3. Finally, (LLR) corresponds to the conditions (BS), (SR), and (EP) in problem (6).

As shown in Section 3.2, neither $\left(\mathrm{IR}_{n}\right)$ nor $\left(\mathrm{IR}_{m n}\right)$ is binding. This intuition is again related to the investment rule of the standard real options model: the option is exercised at a trigger where the option value is positive. Hence, we can set $\phi$ to zero. 
Now, using the arguments of Proposition 3, we can obtain the following proposition.

Proposition 10: In the case of multiple projects, suppose that $C_{M n}$ is sufficiently small relative to $C_{S n}$. Then, $P=\phi=0$. Hence, restricted stock dominates stock options and the base salary.

Proposition 10 suggests that although the time at which the manager exercises the investment option does not necessarily coincide with the time at which he exercises the stock option, the result of the dominance of restricted stock over stock options and the base salary is unaffected, if the manager's effort cost for the later project $C_{M n}$ is sufficiently small relative to the investment cost for the later project $C_{S n}$.

Intuitively, if $C_{M n}$ is not sufficiently small relative to $C_{S n}, \alpha$ may strongly affect $x_{n}^{*}$; that is, $\left|\frac{\partial x_{n}^{*}}{\partial \alpha}\right|$ is sufficiently large. Because $\alpha$ may have a strong effect on both $x_{m}^{*}$ and $x_{n}^{*}$, it may be difficult for the firm to attain the appropriate levels of $x_{m}^{*}$ and $x_{n}^{*}$ only by adjusting $\alpha$. As a result, the firm may have an incentive to exploit $P$ in order to attain the appropriate levels of $x_{m}^{*}$ and $x_{n}^{*}$. Therefore, in this case, stock options may dominate restricted stock; otherwise, restricted stock dominates stock options.

In practice, we can view firms with several independent projects as diversified firms. In addition, the higher $C_{M n}$ relative to $C_{S n}$ can be interpreted such that the start of the additional project involves complicated tasks. Indeed, Berry et al. (2006) find that diversified firms draw their chief executives from a new talented labor pool. Hence, the argument in this subsection suggests that stock options are more likely to dominate restricted stock in diversified firms that require higher managerial skills (e.g., in financial conglomerates).

\subsection{Empire-building tendencies ${ }^{23}$}

Suppose that the manager can obtain private benefits from the start of the project because the board of directors has not enough power to prevent his empire-building tendencies. This extension can easily be incorporated into the basic model in Section 2 by setting $C_{M}=C_{M}^{\prime}-\Gamma$, where $C_{M}^{\prime}$ is the manager's effort cost and $\Gamma$ is the private benefit of the manager. If $\Gamma$ is sufficiently large, then $C_{M}<0$, which may lead to the positive exercise price (see the proof of Proposition 3).

In practice, firms with higher $\Gamma$ can be viewed as firms with weaker corporate gov-

\footnotetext{
${ }^{23}$ This discussion follows the suggestion of an anonymous referee.
} 
ernance. Hence, this discussion implies that stock options are more likely to dominate restricted stock in firms with weaker corporate governance.

\section{The Empirical Implications}

Proposition 4 provides several predictions about investment decisions.

Prediction 1: Investment becomes more deterred as (i) financial crisis risk or authorization and litigation risk becomes higher, (ii) the volatility of the firm's cash flow stream becomes greater, (iii) the manager's task becomes more complicated, and (iv) managerial impatience becomes weaker, if the volatility of the firm's cash flow stream is sufficiently large.

Many empirical studies on real options examine the effect of uncertainty on the investmentcapital ratio rather than on investment timing. Carruth, Dickerson, and Henley (2000) provide a review of the empirical literature on real options investigating the relationship between the investment-capital ratio and proxy measures of uncertainty. A general conclusion is that increased uncertainty leads to a lower investment-capital ratio, at both the aggregate and disaggregate levels. Several recent empirical studies on real options have followed a similar approach. For example, Czarnitzki and Toole (2011) find that firm-level R\&D investment falls in response to higher levels of uncertainty. Other recent empirical studies have attempted to test whether uncertainty reduces the likelihood of investment action. For instance, using plant-level data, Drakos and Kostantinou (2013) suggest that increases in the uncertainty of the real oil price significantly reduce the likelihood of investment action. Irrespective of the differences in estimation procedure, the results of these empirical studies are consistent with our statement of the effect of the volatility of the firm's cash flow on investment decisions.

Bloom, Bond, and van Reenen (2007) provide evidence that, with irreversibility, greater uncertainty reduces the variation of the investment level relative to the capital stock in response to demand shocks. Because their finding can be interpreted as implying that the greater uncertainty reduces the responsiveness of the timing of investment to demand shocks, their estimate is also consistent with the above prediction regarding the volatility of the firm's cash flow stream.

The other statements in Prediction 1 provide new empirical implications. They suggest 
that the investment-capital ratio or the likelihood of investment action can be reduced as the financial crisis risk or the authorization and litigation risk becomes higher, as the manager's task becomes more complicated, or as managerial short-termism becomes weaker. In particular, Berry et al. (2006) find that diversified firms draw their chief executives from a new talented labor pool because these firms require higher managerial skills. Hence, Prediction 1(iii) also implies that the investment-capital ratio or likelihood of investment action can be lower in diversified firms than in focused firms.

Proposition 4 also provides predictions about the amount of restricted stock.

Prediction 2: The grant size of restricted stock is independent of the extent of the financial crisis risk or the authorization and litigation risk. The grant size of restricted stock is larger as the manager's task is more complicated. Furthermore, if the manager's and shareholders' impatience levels are not too different, the grant size of restricted stock is larger as the volatility of the firm's cash flow stream is reduced. The grant size of restricted stock is also larger as managerial impatience becomes weaker, if the volatility of the firm's cash flow stream is sufficiently large.

Existing empirical studies provide predictions only about the amount of stock-based compensation. However, we can suppose that the grant size of the sum of restricted stock and stock options is determined by a mechanism similar to that of the determination of our $\alpha$. In addition, the arguments in Sections 4.5-4.7 also suggest that firms with debt financing, diversified firms involving in complicated business activities, and firms with weak corporate governance may result in a combination of restricted stock and stock options. Hence, we can relate our prediction to the following literature. First, several empirical studies suggest that pay-for-performance measures become smaller as firm income becomes more volatile. For example, Garen (1994), Aggarwal and Samwick (1999), Kraft and Niederprüm (1999), and Dee, Lulseged, and Nowlin (2005) show that executive pay in riskier firms responds less to the firm's stock market performance than does executive pay in less risky firms. If the manager's degree of impatience is not too different from that of shareholders, these findings support the prediction regarding the volatility of the firm's cash flow stream. Furthermore, Jin (2002) and Garvey and Milbourn (2003) extend the above work by decomposing risk into its systematic and idiosyncratic components, and find that idiosyncratic risk has a significant negative effect on pay sensitivities. Jin (2002) 
also indicates that incentives for CEOs likely to face binding short-selling constraints decrease with both systematic and nonsystematic risk. If the idiosyncratic component increases managerial short-termism, these findings are consistent with not only the prediction regarding the volatility of the firm's cash flow stream but also the prediction regarding managerial impatience.

Second, Cyert, Kang, and Kumar (2002) report that default risk is strongly negatively related to the amount of CEO equity compensation. This finding is consistent with the above prediction regarding managerial impatience. On the other hand, managerial impatience decreases as the managerial labor market becomes deeper. If the US has a deeper managerial labor market than elsewhere, our prediction is also consistent with the stylized feature that stock-based compensation for US managers makes up a considerably larger proportion of the average compensation schedule than elsewhere. Furthermore, Bebchuk and Grinstein (2005) indicate that stock-based compensation in the US increased considerably during the period 1993-2003. This tendency coincides with the increased occupational mobility of executives, as suggested by Murphy and Zábojník (2004). These findings also support our predictions regarding managerial impatience.

Finally, the statement regarding financial crisis risk or authorization and litigation risk and the statement regarding the manager's task complexity also provide new empirical implications. In particular, the latter statement can be rephrased so that stock-based compensation is used more in diversified firms than in focused firms.

We now proceed to discuss the likelihood of the use of stock options instead of, or in addition to, restricted stock. During the 2000s, average CEO compensation declined, and restricted stock grants replaced stock options as the most common form of stock compensation. Indeed, although stock options enjoyed favorable accounting treatment and avoided being expensed through the firm's income statements until 2005, they have now lost many of these advantages, at least in the US. This is also one of the main practical reasons why stock option grants first became popular in the 1990s and ceased being so in the 2000s (see Frydman and Jenter (2010), Frydman and Saks (2010), and Murphy (2013)). However, stock options have never fulfilled their intended role in CEO compensation. Hence, we need to consider what economic forces make stock options dominate over restricted stock, although Proposition 3 implies that restricted stock is preferred to stock options. 
In Sections 4.5-4.7, we derived several economic forces that lead stock options to dominate restricted stock. Summarizing the arguments, we obtain the following predictions.

Prediction 3: Stock options can be more likely to be used instead of, or in addition to, restricted stock in firms with new debt financing and more impatient managers, diversified firms involving more complicated business activities, and firms with weaker corporate governance. However, the effect of the presence of outstanding debt on the likelihood of the use of stock options is ambiguous.

In the existing theoretical literature, Dittmann and Maug (2007) suggest that stock options are optimal relative to restricted stock if the manager is risk neutral or has only moderate levels of risk aversion, whereas Kadan and Swinkels (2008) indicate that stock options are optimal relative to restricted stock if the risk-averse manager does not face a higher risk of bankruptcy. By contrast, our predictions imply that stock options may be used instead of, or in addition to, restricted stock in firms with new debt financing and impatient managers (for example, reorganized firms with new debt financing), diversified firms involving complicated business activities (for example, financial conglomerates), and firms with weak corporate governance.

\section{Conclusion}

This paper considers how managers whose objectives are not aligned with those of their firm's shareholders and who face the possibility of project liquidation choose the timing of investment in risky but value-increasing projects, when the managerial compensation schedule is designed endogenously. We examine the situation in which the trigger point for commencing the project cannot be specified in the contract, given incomplete and imperfect information. Using the real options approach, we show that: (i) restricted stock is optimal relative to stock options under various circumstances, although stock options may be more likely to be used instead of, or in addition to, restricted stock in firms with new debt financing and more impatient managers, diversified firms involving more complicated business activities, and firms with weaker corporate governance; and (ii) project start-up is more likely to be deterred by a higher probability of project liquidation, more volatile firm cash flows, higher managerial effort cost, and a lower degree of managerial impatience, whereas stock-based managerial compensation is independent of the liqui- 
dation probability, increasing in the manager's higher effort cost, and decreasing in the volatility of the firm's cash flow stream and the degree of managerial impatience.

Our modeling approach suggests the importance of dynamic considerations, not only in investment timing by managers but also in the optimal design of managerial compensation schedules. One natural extension would involve analyzing how the timing of various organizational decisions is endogenously determined together with managerial compensation schemes (for example, see Habib and Mella-Barral (2007) for the formation and duration of joint ventures, Lambrecht and Myers (2007) for the mechanism of takeovers, and Dangl, Wu, and Zechner (2008) for the replacement of the manager, although these models assume fixed contract payment schedules). The hidden information consideration, as discussed in Morellec and Schürhoff (2011), would also be an important extension. 


\section{Appendix}

Proof of Proposition 1: Let $V\left(x_{t}\right)$ denote the value of the option to invest. Using Ito's lemma, $V\left(x_{t}\right)$ satisfies the differential equation $\frac{1}{2} \sigma^{2} x^{2} V_{x x}(x)+\mu x V_{x}(x)-r V(x)=0$, where $V_{x}=d V / d x, V_{x x}=d^{2} V / d^{2} x$ and $V(0)=0 .{ }^{24}$ Using $V(0)=0$, we can show that the solution is determined by $V(x)=A_{V} x^{\beta_{1}}$, where $A_{V}$ is a constant parameter with $A_{V}>0$ and $\beta_{1}=\frac{1}{2}-\frac{\mu}{\sigma^{2}}+\sqrt{\left(\frac{\mu}{\sigma^{2}}-\frac{1}{2}\right)^{2}+\frac{2 r}{\sigma^{2}}}(>1)$.

Let $F\left(x_{t}\right)$ denote the value of the project, given the current level of the instantaneous cash flow $x_{t}$. Then, it follows from $(1)$ that $F\left(x_{t}\right)=(1-\varepsilon) E\left[\int_{\tau}^{\infty} x_{s} e^{-r s} d s\right]=\frac{(1-\varepsilon) x_{\tau}}{r-\mu}$, where $E$ is the expectation operator (see Dixit and Pindyck (1994)). This is because $F\left(x_{t}\right)$ is the expected discounted value of the cash flow stream. Then, the boundary conditions in this problem are $V\left(x_{F I}\right)=\frac{(1-\varepsilon) x_{F I}}{r-\mu}-C_{S}-C_{M}$ and $\left.\frac{d V(x)}{d x}\right|_{x=x_{F I}}=\frac{1-\varepsilon}{r-\mu}$, where $x_{F I}$ is the full information commencement trigger. The first boundary condition is the value-matching condition, which states that the shareholders' payoff is $\frac{(1-\varepsilon) x_{F I}}{r-\mu}-C_{S}$ $-C_{M}$ at the date at which the commencement option is exercised. ${ }^{25}$ The second boundary condition is the smooth-pasting condition, which ensures that the exercise trigger is chosen to maximize the value of the option to invest. Combining these two conditions with $V(x)$ $=A_{V} x^{\beta_{1}}$, we can derive (2) and (3), given in Proposition 1. $\|$

Proof of Proposition 2: As in the proof of Proposition 1, we can show that $G(x)$ satisfies the differential equation $\frac{1}{2} \sigma^{2} x^{2} G_{x x}(x)+\mu x G_{x}(x)-(r+\xi) G(x)=0$, where $G_{x}$ $=d G / d x, G_{x x}=d^{2} G / d^{2} x$ and $G(0)=0$. Then, repeating a procedure similar to that in the proof of Proposition 1, we can derive (4) and (5), given in Proposition 2. Note that $\gamma_{1} \geq \beta_{1}>1$.

Proof of Proposition 3: As Lemma 1 ensures that (IR) is not binding, we begin with solving problem (6) by dropping (IR) and $0<\alpha \leq 1$ from the set of constraints. After the solution under this assumption is obtained, we check whether the obtained solution satisfies $0<\alpha \leq 1$.

Because (IR) is not binding and the objective function of (6) is decreasing in $\phi$, it follows

\footnotetext{
${ }^{24} V(x)$ satisfies the following Bellman equation: $V(x)=E\left[V(x+d x) e^{-r d t}\right]$. Expanding the righthand side of this equation with Ito's lemma and rearranging it as $d t \rightarrow 0$, we obtain the differential equation introduced here. Note that we remove subscript $t$ from $x_{t}$ and set $d V / d t=0$. This is because the time horizon is infinite and neither $\mu$ nor $\sigma$ depends on time explicitly. Thus, the value function does not depend on time.

${ }^{25}$ Note that the manager needs to be compensated for the loss of $C_{M}$.
} 
from (BS) that $\phi=0$. Substituting $\phi=0$ and $x^{*}$ from (IC) into the objective function of (6), deriving the first-order conditions with respect to $\alpha$ and $P$, and multiplying these conditions by $\left(\frac{x^{*}}{x_{0}}\right)^{\beta_{1}}$, we obtain

$$
\begin{array}{r}
(1-\varepsilon)\left(P-\frac{x^{*}}{r-\mu}\right)-\left[\frac{(1-\alpha)(1-\varepsilon)\left(1-\beta_{1}\right)}{r-\mu}+\beta_{1} \frac{C_{S}-\alpha(1-\varepsilon) P}{x^{*}}\right] \frac{\gamma_{1}(r+\xi-\mu)}{\left(\gamma_{1}-1\right)(1-\varepsilon)} \frac{C_{M}}{\alpha^{2}}=0 \\
(1-\varepsilon) \alpha+\left[\frac{(1-\alpha)(1-\varepsilon)\left(1-\beta_{1}\right)}{r-\mu}+\beta_{1} \frac{C_{S}-\alpha(1-\varepsilon) P}{x^{*}}\right] \frac{\gamma_{1}(r+\xi-\mu)}{\gamma_{1}-1}+\zeta=0
\end{array}
$$

where $\left(\frac{x_{0}}{x^{*}}\right)^{\beta_{1}} \zeta$ is the nonnegative multiplier associated with the constraint (EP).

Combining (A1) and (A2), we obtain

$$
\zeta=-\frac{(1-\varepsilon) \alpha^{2}}{C_{M}}\left[\frac{C_{M}}{\alpha}+(1-\varepsilon)\left(P-\frac{x^{*}}{r-\mu}\right)\right]
$$

Substituting $x^{*}$ from (IC) into (A3) leads to

$$
\zeta=\frac{(1-\varepsilon) \alpha^{2}}{C_{M}}\left[\frac{C_{M}}{\alpha}+(1-\varepsilon) P\right] \frac{r+\gamma_{1} \xi-\mu}{\left(\gamma_{1}-1\right)(r-\mu)}>0 .
$$

Because the multiplier associated with (EP) is positive, we must have $P=0$.

Now, substituting $P=0$ into (A1) and rearranging it with (IC), we show

$$
-\frac{(1-\varepsilon) x^{*}}{r-\mu}-\left[\frac{(1-\alpha)(1-\varepsilon)\left(1-\beta_{1}\right)}{r-\mu}+\beta_{1} \frac{C_{S}}{x^{*}}\right] \frac{x^{*}}{\alpha}=0 .
$$

Further rearranging (A4) with (IC) and $P=0$ yields

$$
\alpha=\frac{\beta_{1}-1}{\beta_{1}} \frac{\gamma_{1}(r+\xi-\mu) C_{M}}{\left(\gamma_{1}-1\right)(r-\mu) C_{S}+\gamma_{1}(r+\xi-\mu) C_{M}} .
$$

Note that $\alpha$, given by (A5), satisfies $0<\alpha<1$ because $\gamma_{1}>\beta_{1}>1$.

Therefore, $\left(\phi^{*}, \alpha^{*}, P^{*}\right)=\left(0, \frac{\beta_{1}-1}{\beta_{1}} \frac{\gamma_{1}(r+\xi-\mu) C_{M}}{\left(\gamma_{1}-1\right)(r-\mu) C_{S}+\gamma_{1}(r+\xi-\mu) C_{M}}, 0\right)$, which is given by (8) of this proposition. Substituting $\left(\phi^{*}, \alpha^{*}, P^{*}\right)$ into (IC), $W_{S}\left(x_{0}\right)$, and $W_{M}\left(x_{0}\right)$, we obtain (7), (9), and (10) of this proposition. Note that $x^{*}>x_{F I}$ because $\gamma_{1}>1$ and $\xi>0$. $\|$ 
Proof of Proposition 4: The results of $\varepsilon$ and $\sigma$ are evident. On the other hand, it is found from $\frac{\partial \beta_{1}}{\partial \xi}=0$ and $\frac{\partial \gamma_{1}}{\partial \xi}>0$ that $\frac{\partial x^{*}}{\partial \xi}<0$ and $\frac{\partial \alpha^{*}}{\partial \xi}<0$ if $\frac{\gamma_{1}}{r+\xi-\mu}<\frac{\frac{\partial \gamma_{1}}{\partial \xi}}{\gamma_{1}-1}$. Indeed, the condition $\frac{\gamma_{1}}{r+\xi-\mu}<\frac{\frac{\partial \gamma_{1}}{\partial \xi}}{\gamma_{1}-1}$ is satisfied if $\gamma_{1}$ is sufficiently close to 1 . It follows from the definition of $\gamma_{1}$ that $\gamma_{1}$ is sufficiently close to 1 if $\sigma^{2}$ is sufficiently large. Hence, we verify that $\frac{\partial x^{*}}{\partial \xi}<0$ and $\frac{\partial \alpha^{*}}{\partial \xi}<0$ if $\sigma^{2}$ is sufficiently large. \|

Proof of Proposition 5: If $\phi$ is allowed to be negative, it must be minimized under the set of constraints in problem (6) because the objective function of (6) is decreasing in $\phi$. As (BS) is not binding, (IR) must be binding to minimize the value of $\phi$. Hence,

$$
\phi=-\left(\frac{x_{0}}{x^{*}}\right)^{\gamma_{1}}\left[\alpha(1-\varepsilon)\left(\frac{x^{*}}{r+\xi-\mu}-P\right)-C_{M}\right]
$$

Substituting (A6) and (IC) into (6), deriving the first-order conditions with respect to $\alpha$ and $P$, and rearranging, we obtain

$$
\zeta_{\phi} \geq\left[\left(\frac{x_{0}}{x^{*}}\right)^{\beta_{1}}-\left(\frac{x_{0}}{x^{*}}\right)^{\gamma_{1}}\right] \frac{(1-\varepsilon)^{2} x^{*}}{\gamma_{1}(r+\xi-\mu)} \frac{\alpha^{2}}{C_{M}} \geq 0
$$

where $\zeta_{\phi}$ is the nonnegative multiplier associated with the constraint (EP), and the inequalities in (A7) follow from $\xi \geq 0$. Note that the inequalities of (A7) are satisfied with equality only if $\xi=0$.

(i) Suppose that $\gamma_{1}>\beta_{1}$ (or $\left.\xi>0\right)$. Then, $\zeta_{\phi}>0$. This implies that $P^{*}=0$. Substituting $P^{*}=0$ and $x^{*}$ from (IC) into (A6), we see that $\phi^{*}=-\left(\frac{x_{0}}{x^{*}}\right)^{\gamma_{1}} \frac{C_{M}}{\gamma_{1}-1}<0$. Given $P^{*}=0$ and (IC), it also follows from the first-order condition with respect to $\alpha$ that

$$
\alpha^{*}=\frac{\gamma_{1}\left(\beta_{1}-1\right)(r+\xi-\mu)\left(\frac{x_{0}}{x^{*}}\right)^{\beta_{1}} C_{M}}{\left(\gamma_{1}-1\right) \beta_{1}(r-\mu)\left(\frac{x_{0}}{x^{*}}\right)^{\beta_{1}} C_{S}+\gamma_{1}\left\{(r-\mu)\left[\beta_{1}\left(\frac{x_{0}}{x^{*}}\right)^{\beta_{1}}-\left(\frac{x_{0}}{x^{*}}\right)^{\gamma_{1}}\right]+\beta_{1} \xi\left(\frac{x_{0}}{x^{*}}\right)^{\beta_{1}}\right\} C_{M}} \in(0,1)
$$

Here, $\alpha^{*} \in(0,1)$ is derived from $\gamma_{1}>\beta_{1}>1$. Substituting this $\alpha^{*}$ into (IC) and using $\gamma_{1}>\beta_{1}$, we obtain $x^{*}>\frac{1}{1-\varepsilon} \frac{\beta_{1}}{\beta_{1}-1}(r-\mu) C_{S}+\frac{1}{1-\varepsilon} \frac{\gamma_{1}}{\gamma_{1}-1}(r+\xi-\mu) C_{M}$. Thus, $x^{*}>x_{F I}$ if $\xi$ is not sufficiently large.

(ii) If $\gamma_{1}=\beta_{1}$ (or $\left.\xi=0\right)$, it is found from the argument of (A7) that $\zeta_{\phi}=0$. Using $\gamma_{1}=$ 
$\beta_{1}$ and $\xi=0$, it follows from the first-order condition with respect to $\alpha$ that

$$
x^{*}=\frac{\beta_{1}}{\beta_{1}-1} \frac{r-\mu}{1-\varepsilon}\left(C_{S}+C_{M}\right)=x_{F I} .
$$

Combining (IC) and (A8) with $\gamma_{1}=\beta_{1}$, we see that

$$
\alpha^{*}=\frac{C_{M}}{C_{S}+C_{M}-(1-\varepsilon) P^{*}} .
$$

Hence, it follows from (A9) with $1 \geq \alpha$ and $P \geq 0$ that

$$
0 \leq P^{*} \leq \frac{C_{S}}{1-\varepsilon}
$$

Substituting (A9) into (A6) and rearranging it with (A8) yields

$$
\phi^{*}=-\left(\frac{x_{0}}{x^{*}}\right)^{\beta_{1}} \frac{C_{M}\left(C_{S}+C_{M}\right)}{\left(\beta_{1}-1\right)\left[C_{S}+C_{M}-(1-\varepsilon) P^{*}\right]}<0
$$

Thus, the optimal contract is given by (A9)-(A11). The optimal trigger point is given by (A8). $\|$

Proof of Proposition 6: In firm maximization problem (11), neither (IRA) nor (IRB) is binding, as shown in Section 3.2. This intuition is again related to the investment rule of the standard real options model: The option is exercised at a trigger where the option value is positive. Hence, we can set $\phi$ to zero.

Given these findings, we solve (11). Deriving the first-order conditions with respect to $\alpha$ and $P$ and rearranging them with $\frac{\partial x_{j}^{*}}{\partial \alpha}=-\frac{C_{M}}{(1-\varepsilon) \alpha^{2}} \frac{\partial x_{j}^{*}}{\partial P}(j=A, B)$, we obtain

$$
\begin{aligned}
\zeta_{\sigma^{2}} & =\frac{(1-\varepsilon) \alpha^{2}}{C_{M}}\left[(1-\varepsilon)\left(\frac{x_{A}^{*}}{r-\mu_{A}}-P\right)-\frac{C_{M}}{\alpha}\right]\left(\frac{x_{0}}{x_{A}^{*}}\right)^{\beta_{A}} \\
& -\frac{(1-\epsilon) \alpha^{2}}{C_{M}} \eta\left\{\left[(1-\varepsilon)\left(\frac{x_{A}^{*}}{r+\xi-\mu_{A}}-P\right)-\frac{C_{M}}{\alpha}\right]\left(\frac{x_{0}}{x_{A}^{*}}\right)^{\gamma_{A}}\right. \\
& \left.-\left[(1-\varepsilon)\left(\frac{x_{B}^{*}}{r+\xi-\mu_{B}}-P\right)-\frac{C_{M}}{\alpha}\right]\left(\frac{x_{0}}{x_{B}^{*}}\right)^{\gamma_{B}}\right\},
\end{aligned}
$$

where $\eta$ and $\zeta_{\sigma^{2}}$ are the nonnegative multipliers associated with $\left(\mathrm{IC} \sigma^{2}\right)$ and $P \geq 0$, 
respectively. It follows from $\left(\mathrm{IC} x_{A}^{*}\right)$ that

$$
\frac{(1-\varepsilon) x_{A}^{*}}{r-\mu_{A}}>\frac{(1-\varepsilon) x_{A}^{*}}{r+\xi-\mu_{A}}>(1-\varepsilon) P+\frac{C_{M}}{\alpha} .
$$

Furthermore, the complementary slackness of the Kuhn-Tucker conditions implies that

$$
\begin{gathered}
\eta\left\{\left[(1-\varepsilon)\left(\frac{x_{A}^{*}}{r+\xi-\mu_{A}}-P\right)-\frac{C_{M}}{\alpha}\right]\left(\frac{x_{0}}{x_{A}^{*}}\right)^{\gamma_{A}}\right. \\
\left.-\left[(1-\varepsilon)\left(\frac{x_{B}^{*}}{r+\xi-\mu_{B}}-P\right)-\frac{C_{M}}{\alpha}\right]\left(\frac{x_{0}}{x_{B}^{*}}\right)^{\gamma_{B}}\right\}=0 .
\end{gathered}
$$

Substituting (A14) into (A12) and observing it with (A13), we show that $\zeta_{\sigma^{2}}>0$; that is, $P=0$. $\|$

Proof of Proposition 7: Using standard arguments (see Lambrecht and Myers (2007, 2008)), it is straightforward to show that the optimal default threshold is given by (12). The derivation of $W_{M}^{b}\left(x_{i}^{*}\right)$ and $D\left(x_{i}^{*}\right)$ is also standard (see Lambrecht and Myers (2007, 2008)). Finally, the option is exercised at a trigger where the option value is positive. Hence, $W_{M}^{b}\left(x_{i}^{*}\right)>0$. $\|$

Proof of Proposition 8: As in the proof of Proposition 1 or 2, the value of the option to invest, $H\left(x_{t}\right)$, is determined by $H(x)=A_{H} x^{\beta_{1}}$, where $A_{H}$ is a constant parameter with $A_{H}>0$. The boundary conditions in this problem are

$$
H\left(x_{i}^{*}\right)=W_{M}^{b}\left(x_{i}^{*}\right)
$$

and

$$
\left.\frac{d H(x)}{d x}\right|_{x=x_{i}^{*}}=\frac{\alpha(1-\varepsilon)}{r+\xi-\mu}-\frac{\alpha(1-\varepsilon) \gamma_{2}\left(x_{i}^{*}\right)^{\gamma_{2}-1}}{\left(x_{d}^{*}\right)^{\gamma_{2}}}\left(\frac{x_{d}^{*}}{r+\xi-\mu}-\frac{s}{r+\xi}\right)
$$

where the first boundary condition is the value-matching condition and the second boundary condition is the smooth-pasting condition. Combining (A15) and (A16) with $H(x)=$ $A_{H} x^{\beta_{1}}$, we obtain (15). The derivation of (16) and (17) is standard (see Lambrecht and Myers $(2007,2008)$ ), and $W_{M}^{b}\left(x_{0}\right)>0$ is evident from Proposition 7 . ॥

Proof of Proposition 9: It is straightforward to see that $\phi=0$ and $W_{M}^{b}\left(x_{0}\right)>0$ in 
problem (18). Hence, we only need to solve problem (18) by dropping the variable $\phi$ and the constraint $W_{M}^{b}\left(x_{0}\right) \geq 0 .{ }^{26}$ Deriving the first-order conditions with respect to $\alpha$ and $P$ and rearranging them with $\frac{\partial x_{i}^{*}}{\partial \alpha}=-\frac{C_{M}}{(1-\varepsilon) \alpha^{2}} \frac{\partial x_{i}^{*}}{\partial P}$ from (15), we can show that

$$
\zeta_{b}=\frac{(1-\varepsilon)^{2} \alpha^{2}}{C_{M}}\left[\frac{x_{i}^{*}}{r-\mu}-P-\frac{s}{r}-\frac{C_{M}}{\alpha(1-\varepsilon)}-\left(\frac{x_{i}^{*}}{x_{d}^{*}}\right)^{\beta_{2}}\left(\frac{x_{d}^{*}}{r-\mu}-\frac{s}{r}\right)\right],
$$

where $\left(\frac{x_{0}}{x_{i}^{*}}\right)^{\beta_{1}} \zeta_{b}$ is the nonnegative multiplier associated with $P \geq 0$. As long as the investment option is exercised, it follows from (15) with $\gamma_{1}>1$ and $\gamma_{2}<0$ that the right-hand side of $(\mathrm{A} 17)$ is positive if $\xi(\geq 0)$ is sufficiently small. Hence, we must have $P=0 . \|$

Proof of Proposition 10: Solving problem (20) with the arguments of Proposition 3, we can obtain

$$
\begin{aligned}
\zeta_{m n} & =\frac{\left(1-\varepsilon_{m}\right) \alpha^{2}}{C_{M m}}\left\{\left(1-\varepsilon_{m}\right)\left[\frac{x_{m}^{*}}{r-\mu_{m}}-P-\frac{C_{M m}}{\alpha\left(1-\varepsilon_{m}\right)}\right]\left(\frac{x_{0}}{x_{m}^{*}}\right)^{\beta_{m}}\right. \\
& +\left(1-\varepsilon_{n}\right)\left[\frac{x_{n}^{*}}{r-\mu_{n}}-\frac{C_{S n}}{\alpha\left(1-\varepsilon_{n}\right)}\right]\left(\frac{x_{0}}{x_{n}^{*}}\right)^{\beta_{n}} \\
& \left.-\left(1-\varepsilon_{n}\right)(1-\alpha)\left(\beta_{n}-1\right)\left[\frac{x_{n}^{*}}{r-\mu_{n}}+\frac{\beta_{n}}{\beta_{n}-1} \frac{C_{S n}}{1-\varepsilon_{n}}\right] \frac{\frac{C_{M n}}{\alpha^{2}}}{C_{S n}+\frac{C_{M n}}{\alpha}}\right\},
\end{aligned}
$$

where $\zeta_{m n}$ is the nonnegative multiplier associated with $P \geq 0$. Note that (A18) can be derived using the relation $\frac{\partial x_{n}^{*}}{\partial \alpha}=-\frac{C_{M n}}{\alpha^{2}} \frac{x_{n}^{*}}{C_{S n}+\frac{C_{M n}}{\alpha}}$ from $\left(\mathrm{IC}_{n}\right)$. Now, if $C_{M n}$ is sufficiently small relative to $C_{S n}$, the last term in the large bracket of (A18) is sufficiently close to zero. Hence, it follows from $\left(\mathrm{IC}_{m}\right)$ and $\left(\mathrm{IC}_{n}\right)$ that $\zeta_{m n}>0$. Thus, we must have $P=0$. $\|$

\footnotetext{
${ }^{26}$ Again, we can drop $1 \geq \alpha>0$.
} 


\section{References}

Aggarwal, R. K., and Samwick, A. A., 1999, The other side of the tradeoff: The impact of risk on executive compensation, Journal of Political Economy, 107, 65-105.

Bebchuk, L., and Grinstein, Y., 2005, The growth of executive pay, Oxford Review of Economic Policy, 21, 283-303.

Berry, T.K., Bizjak, J.M., Lemmon, M.L., and Naveen, L., 2006, Organizational complexity and CEO labor markets: Evidence from diversified firms. Journal of Corporate Finance, 12, 797-817.

Bloom, N., Bond, S., and Reenen J.-V., 2007, Uncertainty and investment dynamics, Review of Economic Studies, 74, 391-415.

Carruth, A., Dickerson, A., and Henley, A., 2000, What do we know about investment under uncertainty? Journal of Economic Surveys, 14, 119-154.

Cyert, R. M., Kang, S.-H., and Kumar, P., 2002, Corporate governance, takeovers, and top-management compensation: Theory and evidence, Management Science, 48, 453-469.

Czarnitzki, D., and Toole, A. A., 2011, Patent protection, market uncertainty, and R\&D investment, Review of Economics and Statistics, 93, 147-159.

Dangl, T., Wu, Y., and Zechner, J., 2008, Market discipline and internal governance in the mutual fund industry, Review of Financial Studies, 21, 2307-2343.

Dee, C. C., Lulseged, A., and Nowlin, T. S., 2005, Executive compensation and risk: The case of internet firms, Journal of Corporate Finance, 12, 80-96.

de Meza, D., and Webb, D. C., 2007, Incentive design under loss aversion, Journal of the European Economic Association, 5, 66-92.

Dittmann, I., and Maug, E., 2007, Lower salaries and no options? On the optimal structure of executive pay, Journal of Finance, 62, 303-343.

Dixit, A. K., and Pindyck, R. S., 1994, Investment under Uncertainty, (Princeton University Press, Princeton).

Drakos, K., and Konstantinou, P. T., 2013, Investment decisions in manufacturing: Assessing the effects of real oil prices and their uncertainty, Journal of Applied Econometrics, $28,151-165$.

Frydman, C., and Jenter, D., 2010, CEO Compensation, NBER Working Paper, No. 16585 .

Frydman, C., and Saks, R. E., 2010, Executive compensation: A new view from a longterm perspective, 1936-2005, Review of Financial Studies, 23, 2099-2138.

Garen, J. E., 1994, Executive compensation and principal-agent theory, Journal of Political Economy, 102, 1175-1199.

Garvey, G., and Milbourn, T., 2003, Incentive compensation when executives can hedge the market: Evidence of relative performance evaluation in the cross-section, Journal of Finance, 58, 1557-1581. 
Grenadier, S. R., and Wang, N., 2005, Investment timing, agency, and information, Journal of Financial Economics, 75, 493-533.

Habib, M., and Mella-Barral, P., 2007, The role of knowhow acquisition in the formation and duration of joint ventures, Review of Financial Studies, 20, 189-233.

Hall, B. J., and Murphy, K. J., 2002, Stock options for undiversified executives, Journal of Accounting Economics, 33, 3-42.

Hori, K., and Osano, H., 2009, Optimal timing of management turnover under agency problems, Journal of Economic Dynamics and Control, 33, 1962-1980.

Hugonnier, J., and Morellec, E., 2007, Corporate control and real investment in incomplete markets, Journal of Economic Dynamics and Control, 31, 1781-1800.

Jin, L., 2002, CEO compensation, diversification, and incentives, Journal of Financial Economics, 66, 29-63.

Kadan, O., and Swinkels, J. M., 2008, Stocks or options? Moral hazard, firm viability, and the design of compensation contracts, Review of Financial Studies, 21, 451-482.

Karatzas, I. and Shreve, S.E., 1998, Methods of Mathematical Finance, (Springer, Berlin).

Kraft, K., and Niederprüm, A., 1999, Determinants of management compensation with risk-averse agents and dispersed ownership of the firm, Journal of Economic Behavior and Organization, 40, 17-27.

Lambrecht, B. M., and Myers, S. C., 2007, A theory of takeovers and disinvestment, Journal of Finance, 62, 809-845.

Lambrecht, B. M., and Myers, S. C., 2008, Debt and managerial rents in a real-options model of the firm, Journal of Financial Economics, 89, 209-231.

Lyandres, E., and Zhdanov, A., 2010, Accelerated investment effect of risky debt, Journal of Banking and Finance, 34, 2587-2599.

Mæland, J., 2006, Valuation of an irreversible investment: Private information about a stochastic variable, mimeo.

McDonald, R., and Siegel, D., 1986, The value of waiting to invest, Quarterly Journal of Economics, 101, 707-728.

Morellec, E., 2004, Can managerial discretion explain observed leverage ratios? Review of Financial Studies, 17, 257-294.

Morellec, E., and Schürhoff, N., 2011, Corporate investment and financing under asymmetric information, Journal of Financial Economics, 99, 262-288.

Murphy, K. J., 2013, Executive compensation: Where we are, and how we got there, Handbook of the Economics of Finance 2A, 211-356, (Elsevier, Amsterdam).

Murphy, K. J., and Zábojník, J., 2004, CEO pay and appointments: A market-based explanation for recent trends, American Economic Review, 94, 192-196.

Ross, S. A., 2004, Compensation, incentives, and the duality of risk aversion and riskiness, Journal of Finance, 59, 207-225.

Shibata, T., 2009, Investment timing, asymmetric information, and audit structure: A real options framework, Journal of Economic Dynamics and Control, 33, 903-921. 